Military Technical College

Kobry El-Kobbah,

Cairo, Egypt.

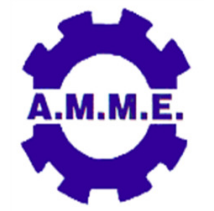

$17^{\text {th }}$ International Conference

on Applied Mechanics and

Mechanical Engineering.

\title{
OCEANIC WAVE GLIDER OVERVIEW; DEVELOPMENT AND APPLICATIONS
}

\author{
A. M. Ahmed ${ }^{*}$
}

\begin{abstract}
The wave glider demonstrates a new unmanned surface vehicles (USV) platform with unique capabilities for continuous data collection, in a complex marine environment and could operate with no costly deep water mooring or shipping operations. The instruments are powered by solar panels on the surface component, making the wave glider a self-sustaining vehicle. The wave glider uses the endless power of the ocean waves to propel itself negating the need of a motor: a technological leap from typical AUVs powered by motors and buoys with expensive mooring systems. In this paper, we discuss the main types of AUVs and the development of wave glider as a solution for most challenges facing AUVs. Wave glider can be used for intelligence, surveillance, monitoring exclusive economic zones for fishing and other economic resources that are very important to coastal countries.

The purpose of studying wave glider is to discuss the efficiency and functionality of it to replace many AUVs for a variety of applications. The results of study demonstrate that the wave glider is applicable in commercial and economical sectors and also in military operations. Wave glider offers a cheaper, more economical and environmentally sound method of monitoring the seas and obtain greater amounts of information at lower costs also has no need for ship time, mooring lines and at-sea servicing.
\end{abstract}

\section{KEY WORDS}

Autonomous underwater vehicle (AUVs), wave glider and hydrofoils.

\footnotetext{
* Egyptian Armed Forces.
} 


\section{INTRODUCTION}

The oil and gas industry have increasingly been venturing further and deeper offshore in search for oil and gas. Deepwater (water depth between $200 \mathrm{~m}$ and $1500 \mathrm{~m}$ ) and ultra-deepwater (water depth greater than $1500 \mathrm{~m}$ ) subsea installations have increased beyond the limits of human divers [1], [2]. This motivated the development of autonomous underwater vehicles (AUVs). AUVs are remarkable machines that revolutionized the process of gathering ocean data as shown in Fig 1. Most of the advances in AUV capabilities aimed at reaching new application scenarios and decreasing the cost of ocean data collection, by reducing ship time and automating the process of data gathering with accurate geo location [3].

During the last decades, AUVs have gone through remarkable developments. In the late eighties and early nineties, the first prototypes required an extraordinary effort and ingenious engineering solutions to compensate for the technological limitations in terms of computational power, batteries, and navigation sensors. AUVs have gradually moved from the controlled academic environment into challenging operational scenarios, covering scientific, commercial and military applications. With the improvements in computational power, battery technology and miniaturization of electronic systems, AUVs had become less cumbersome and more applicable to be used as test beds for new techniques for data processing. The access to operational vehicles was further facilitated and more prototypes became accessible for testing new algorithms and solutions as smaller, lighter and less expensive equipments have become available [4].

An underwater glider (UG) is special types of AUVs that are used in oceanographic sensing and data collection. They are attractive because of autonomy and capability for long-range, extended duration deployment. At deployment, UGs are negatively buoyant and therefore tends to dive, during which its wings convert the downward motion into the horizontal plane, thus producing a forward force. Once a predetermined depth is reached, the vehicle changes its buoyancy to become positively buoyant [5]. This can be done by pumping oil from an internal bladder to external bladder to the vehicle, thus increasing the vehicle volume but keeping the mass constant as shown in Fig. 2.

The wave glider demonstrates a new Unmanned Surface Vehicles (USV) platform with unique capabilities for continuous data collection, in a complex marine environment and could operate with no costly deep water mooring or shipping operations. Wave glider is a hybrid sea surface and underwater vehicle consisting of a submerged glider, attached via a tether, to a surface float. The vehicle is propelled by the submerged glider which can convert the vertical ocean wave motion energy into forward thrust. As this vehicle was designed specifically to collect data from the ocean, the vehicle is capable of accommodating various kinds of sensors which may be used for different applications during missions [6].

Wave glider has instruments on the surface component that can be customized for Acoustic Doppler Current Profiler (ADCP) and Conductivity, Temperature and Depth of the Ocean (CTD) measurements, passive monitoring of marine life and other commercial and defense applications. The instruments are powered by solar panels on the surface component, making the wave glider a self-sustaining vehicle which 
transmits data to land in real-time sequence, allowing for accurate and easy monitoring of the vehicle's trip and the data collected as shown in Fig. 3.

\section{AUVs DEVELOPMENT}

AUVs are programmable robotic vehicles that drift, cruise or glide through the ocean. The AUVs can be programmed to go anywhere and record data throughout the entire journey or only at certain points [7]. Some AUVS can make their own decisions based on the data received and interpreted along the way. They are very simple to deploy and easy to control from a ship or land-based control center. AUVs communicate periodically through underwater beacons or real-time via satellite as shown in Fig. 4. The main reason for using AUVs is that they are the most effective way to obtain a large series of data. As result of their low cost and high level of safety, AUVs usually offer the best or only option for many missions. They are the newest technology for obtaining data and much advancement is still underway [8].

AUVs have not been proven to be cost effective at deep depths. Three AUVs have gone to depths greater than 6000 meters, including the Naval Ocean Systems Center's Underwater Search System (AUSS), the French vehicle EPAULARD, and the Soviet Union's MT-88. The deep water AUV systems proved to be too expensive regarding equipment and operational costs due to the complexity and size required to reach those depths. A large portion of research and development in the United States has been for military purposes as shown in Fig.5. Vehicles weighing an excess of 6 metric tons have been built. They cost millions of dollars and require large support vessels and have limited handling capabilities.

In 1992, the Institute of Industrial Science University of Tokyo developed the first shuttle -type underwater glider ALBAC [9]. In recent years the scientific community has seen a need for small, high performance, low cost AUVs. The lower cost of the AUVs allows scientists to deploy greater numbers of them. This results in a larger number of data points being collected for analysis. They also allow more dangerous missions to be attempted without the fear of losing extremely expensive pieces of equipment.

In 1991 and 1992 MIT Sea Grant College Program's AUV Laboratory constructed a vehicle called the Odyssey; it underwent trials in the Atlantic Ocean off of New England before being deployed from the Nathaniel B. Palmer off of Antarctica in early 1993. The success of this program, led to the creation of a second generation of the Odyssey: The Odyssey IV weighs $1000 \mathrm{lbs}$. and is $6.5 \mathrm{ft}$. long it has twin side-mounted thrusters that can propel up to 3 knots which also proved to be very successful in autonomously taking measurements up to 1,400 meters under Arctic sea-ice as shown in Fig.6. AUVs are usually shaped similar to a torpedo. They can be driven by buoys, a battery or a motor with a propeller, wave energy driven or solar driven in conjunction with batteries and a propeller [10].

Autonomous Surface Crafts (ASC) started to gain momentum, [11], [12]. ASCs are easier to develop than AUVs from the point of view of the navigation, having access, at least in principle, to GPS. Experimentation with ASCs makes it possible to decouple navigation difficulties from all the other sources of disturbances peculiar to the marine 
environment. So, it may have been expected to see ASCs as predecessors of AUVs. The progress in the two fields had proceeded at best in parallel. However, ASCs have now a clear potential for applications in defense and security and for hazardous inspection missions [13], [14]. From a scientific viewpoint, ASCs are an ideal vehicle to collect samples from the sea surface, for oceanographic and marine biology purposes. They can also be efficiently used as test-bed for multi-vehicle operations.

Another class of vehicle is oceanographic gliders as in Fig.7. These vehicles were designed primarily for oceanographic purposes, with the mission of sampling in depth of the water column when moving from one station to another. Usually equipped with standard CTD probes, gliders do not have propellers, but change their buoyancy and asset by active ballast variation and displacement; Each time the vehicle resurfaces; it gets into GPS and satellite contact, transmits the data to a ground station, and receives further indication on the next route to pursue. Because the path following accuracy and speed are not to be expected from gliders, they have been very versatile regarding mission reconfiguration and adaptation, and in coordinated missions [15], [16].

The first wave glider was delivered in 2008. In 2011, NOAA's NDBC deployed the first operational wave gliders to monitor real time observations throughout the Gulf of Mexico. They also released a second wave glider to record tsunami observations and data, also helped the NDBC enhance coastline inundation, maritime safety, oceanographic and meteorological observations. Liquid Robotics has proved the success of the wave glider with a 60,000-kilometer journey called PACX. Four wave gliders traveled from San Francisco to Hawaii and then broke into two pairs. One pair proceeded to Australia while the other traveled to Japan [17].

\section{UNDERWATER GLIDERS DEVELOPMENT}

ALBAC was first prototype glider that moved by gliding without any propeller system [18] as shown in Fig. 8. It has a cylindrical body with fixed wings to develop maximum lift force and actuators to control the buoyancy of the glider [19] as shown in Fig.9. It is $1.4 \mathrm{~m}$ long, $120 \mathrm{~cm}$ in wide, weighs $45 \mathrm{~kg}$, and can dive to depths of $300 \mathrm{~m}$ at speeds of one to two knots. It has horizontal tail fins which change angle at inflection from downwards to upwards gliding, a feature not present in other gliders. The vehicle has no external communication ability. It was designed to carry scientific measurement devices to a fixed destination at a 20 degree gliding angle. After reaching its destination at depth $300 \mathrm{~m}$, it becomes positive buoyant. The trajectory is controlled by changing the center of buoyancy.

In 1995 The Naval Research's Autonomous Oceanographic Sampling Network (AOSN) developed three underwater gliders Slocum, Spray and Seaglider, similar in size and design [20] for oceanographic sampling. The Webb Research Corp's (WRC) optimized the Slocum for missions in shallow coastal environments which required fast turning and vertical velocity [21]. It had a single stroke pump to shift water in and out for volume control. A rudder was used to control the turning movement and pitch control was by shifting mass. The Scripps Institution of Oceanography's (SIO) overcome these limitations by developing a hull similar to the Slocum battery glider but with a more hydrodynamic shape giving it about fifty percent less drag than the Slocum battery and used a reciprocating pump capable of operating under higher 
pressure. This resulting glider, known as Spray [22] was electric-powered vehicle optimized for use in the deep ocean where a long duration is paramount as shown in Fig.10. [23] [24]. Each of these vehicles uses battery power to control the buoyancy. The Slocum battery is controlled by different methods. The pitch and roll is controlled by translating and rotating the internal battery packs. The communication and GPS antennas are embedded in a vertical stabilizer, which rises above the ocean surface when the vehicle is pitched; forward. The spray was targeted for long-range up to $4700 \mathrm{~km}$ and down to 1500 meters depth by optimizing the use of energy [25].

The Webb Research Corp's (WRC) developed Slocum Thermal for long duration missions in waters with a well-developed thermo cline [26]. Because temperature and heat vary at the different depths, heat is absorbed and released, causing the volume of working fluid to change [27]. The thermal cycle has a very low efficiency, approximately $3 \%$, due to the small temperature differences but the working range is more as compare to the existing underwater gliders shown in Fig 11. The propulsion of the vehicle is derived from harnessing the energy of the thermal gradient between the ocean's surface and bottom for use as the vehicle's propulsion. Slocum thermal is nearly identical to Slocum battery except for its thermal buoyancy system and using roll rather than a movable rudder to control turning. The specifications of the Spray, Slocum (Battery \& Thermal) gliders are shown in Table 1.

The University of Washington's designed Seaglider enclose in a hydrodynamic fiberglass fairing supporting wings, vertical stabilizer and tailing antenna [28], [29] as shown in Fig. 12. It had low drag hydrodynamic shape that retained a laminar boundary layer forward of its maximum diameter. The Seaglider using an efficient use of energy allows it to operate one-year $4600 \mathrm{~km}$ missions [30]. Seaglider uses a hydrodynamic aluminum pressure hull that is contained within a free-flooded fiberglass fairing that supports the wings. The flooded aft section is used to carry self-contained instruments on the both vehicles. By improving the strength and hydrodynamic shape of the hull in 2002 [31], they developed Deepglider, which was similar in size to the Sea glider as shown in Fig. 13. The hull of glider attained a maximum strength to weight ratio by using the thermoset resin and carbon fibers to achieve a $6000 \mathrm{~m}$ operational depth. The buoyancy engine of the Deepglider is identical to the Seaglider, the difference being its ability to work under high pressure and control more volume due to the capacity of its buoyancy controls actuators, as shown in Fig. 14. In both gliders, it is the movements of internal masses which control the pitch and yaw of the vehicle while gliding, and also raise the antenna for communication and GPS navigation. The specifications of the both vehicles are shown in Table 2.

The Spray, Slocum (Battery \& Thermal), Seaglider and Deepglider are very similar in size and general characteristics. They were designed with the same objectives, specifically in being small and easily deployed and recovered by only a couple of people. Currently, various institutions are starting the investigation of long duration, highly efficient, slow-speed, powered autonomous underwater vehicles. These investigations will lead to the development of new highly optimized efficient wings.

The majority of UGs developed are for oceanographic measurement, with a few specifically built for marine surveillance. One example is US Navy's Persistent Littoral Undersea Surveillance Network (PLUSNet) XRAY glider, developed in 2006, shown in 
Fig. 15. PLUSNet uses unmanned underwater vehicles (UUVs) and (AUVs) to monitor shallow-water environments from fixed positions on the ocean floor or by moving through the water to scan large areas for extended periods of time [32]. The vehicle is the largest of all of the underwater gliders (6.1 meter wing span), which is an advantage in terms of hydrodynamic efficiency and space for energy storage and payload [33], [34]. It was specifically built for the purpose of marine surveillance and other remote sensing application of interest to the United States Navy. According to military doctrine it can be deployed quickly and covertly and then stay in operation for months. It can be programmed to monitor large areas of the ocean (maximum ranges exceeding $1000 \mathrm{~km}$ with on-board energy supplies). The glider is very quiet, making it hard to detect using passive acoustic sensing. The XRay glider is hoped to achieve 13 knot cruise speeds, have a $1200-1500 \mathrm{~km}$ range, and be able to remain on-station up to 6 months in partial buoyant glides [35].

The new blended wing-body design was to improve the propulsive efficiency of legacy gliders such as the Slocum, Spray and Seaglider. The ZRAY glider is modified form of the XRAY glider that was completed in March 2010, having capacity of $1600 \mathrm{lb}$ dry weight and operational depth $300 \mathrm{~m}$ [36] as shown in Fig. 16. A comparison of the payload capacity of existing gliders is shown in Fig. 17.

\section{WAVE GLIDER OVERVIEW}

As the fleet of AUVs increases, and long-term missions are considered, the energy efficiency of the vehicles becomes a key issue. So far progress in endurance has been linked to progress in electrical batteries; new generation batteries allow for more energy storage while at the same time reducing size and weight [37]. This allows an increase in mission time even for small lightweight vehicles. However, this is not yet enough to guarantee mission times of more than few days at the very best. Moreover, the increase in functionalities carried out increase the energy requirements. Acoustic modems do not come cheaply, in terms of energy budget; some payloads are also energy-consuming devices. The group led by Blidberg had pioneered the investigation on solar-powered AUVs; with solar panels accumulating energy when the vehicle is at the surface [38].

Different types of Unmanned Surface Vehicles (USV) have been invented to aid humans in meeting the demand for obtaining data from the ocean. Nevertheless, most USVs suffer from lack of power while trailing. As a result, the trial distance is limited by the power source on board. As the sizes of USVs are generally small, the power source onboard is usually insufficient to accomplish missions with long time trials [39]. In order to solve this problem, the wave glider has been developed, which demonstrates a new USV platform with unique capabilities for continuous data collection, in a complex marine environment.

Liquid Robotics has developed a completely autonomous vehicle that draws all of its power from the sun and the sea as shown in Fig.18. The propulsion works primarily off of the buoyancy of a surface float that pulls the wings upward and the negative buoyancy of the wings causing them to sink. The electrical system on board is powered by solar panels on the floating surface component which power the remote control and onboard instruments that allow the wave glider to constantly monitor and 
test different aspects of the ocean. In 2010, the vehicle was tested and operated in the ocean for 600 days, which exceeded the original target of 1 year. Therefore the design has proven to be a successful platform for the purpose of long term trials.

Wave glider is the first unmanned autonomous marine robot to use only the ocean's endless supply of wave energy for propulsion (no manpower, no emissions, no refueling).It represents a technological leap from typical AUVs powered by motors and buoys with expensive mooring systems. The innovator of the wave glider, Roger Hine, started to work on a prototype in 2005 . His main objective was to create a new type which could operate with no costly deep water mooring or shipping operations. The final design is a hybrid sea surface and underwater vehicle consisting of a submerged glider, attached via a tether, to a surface float. The subsurface wing system, called the swimmer, has a frame on a longitudinal axis, and fins that rotate about the axis. The fins are laminar and the frame consists of a rigid bar. The fin system is comprised of 12 identical laminar fins. This subsurface glider looks similar to the Slocum glider except instead of one pair of wings there are six sets of wings down the vehicle's side. A rising wave lifts the float, causing the tethered sub to rise. The articulated wings on the sub are pressed down and the upward motion of the Sub becomes an up-and-forward motion, in turn pulling the float forward and off the wave. This causes the sub to drop, the wings pivot up and the sub moves down-and-forward as shown in Fig.19 and Fig.20 and Table 3. This process is repeated again and again as long as there is wave motion on the surface even the smallest amount as shown in Fig.21. The vehicle moves quite slowly and high currents are a problem. The float contains a system for satellite communication and tracking which allows for steering using the rudder. The tether comprises of a device to detect twisting and another device to correct the twisting.

Wave glider is equipped with GPS and sophisticated computers for navigation and payload control with satellite communication systems and with state of the art ocean sensors to monitor and measure the environment around it. The specifications of the wave glider are shown in table (4). The wave glider is commonly fitted with an ADCP, an acoustic modem, vessel automation identification system receivers, passive acoustics for animal monitoring and a few other instruments to measure meteorological and oceanographic conditions. Because the wave gliders are mobile, they can be deployed from any port or harbor, complete their long missions and return back to any port or harbor to be serviced.

\section{Original Structure \& Working Principal}

A Wave glider was designed with hybrid sea-surface float and submerged propulsion systems, connected by an umbilical (tethered) cored. The breakdown of its structure is illustrated in Fig. 22. While operating, the vertical wave energy captured by the float will translate to the submerged glider through a tether, and directly turn into forward motion [40]. Surface waves pull the submerged glider, while the float is passing through a wave crest. The wings turn to a certain angle, due to the inertia of the water, while the submerged glider is pulled up and down. Because of this angle, the glider's wings convert wave-powered vertical motion into forward motion. 
The wave energy propulsion system is powered purely by mechanical energy, which means that there will be no electrical power supplying the submerged part in terms of forward motion. This propulsion system is effective, since there is no energy lost from conversion. Therefore, the total energy lost, as a result of converting renewable energy into another form of secondary energy, can be eliminated. However, according to the data provided for wave glider, the maximum speed of the vehicle is only 2.25 knots, which is dominated by the magnitude of the wave. In this case, the wave glider is only suitable for missions with a long trial time. If the mission consisted of a quick trial with a time limitation, the glider may not be able to complete it.

The magnitude of motion caused by propulsion is dominated by the difference between two wave crests. In this case, sea state is introduced as a parameter describing the general wave magnitude. Table 5 presents data which has been collected by Hine et al. (2009) regarding the relationship between sea state and the general speed of the wave glider. It can be shown that the wave glider's speed is proportional to sea state. However, it is not known, whether the direction of a high speed wave will influence the direction of the wave glider. Despite that, it has been demonstrated by the designer that the wave glider can trail, independent of wave direction. However it can be predicted that the direction will be influenced by the wave direction, during a high sea state.

\section{Operation in High Sea State}

The wave glider can survive extreme sea conditions. Basically, the wave glider's mechanical endurance is only limited by its robustness. As expected, in 2007, the wave glider was capable of navigating in weather conditions associated with 10+ foot tides and $40+$ knot winds. This proved its mechanical stability. As the sea state increases, the energy consumed in the waves will keep rising. This leads to the buoyancy generated by the float being neutralized by the vertical drag force generated by the inertia of the submerged glider in the water. This causes the surface float to dive into the larger tides. This phenomenon occurs when the energy consumption of the waves exceeds the wave glider's energy capturing capacity. This phenomenon tends to protect the structure from damage by the waves, since the wave energy is reduced below the water surface and continues to decrease as the depth increases. Hence, the wave glider can be protected under the high sea state situation. A larger model can be generated for capturing more energy from the waves during a high sea state. When considering the possibility of working under the high sea state, improvement on designs could increase this effectiveness by reinforcing the wings [41].

\section{Wave Glider Applications}

The wave glider is an example of the new cutting-edge technology being utilized. It will tow an ocean bottom seismic device to a pre-determined location to be deployed, free floating down to its operating location. The wave glider will circle around above the seismic device on the ocean's surface, receiving data transmitted via an acoustic modem. The wave glider will transmit the data it receives to a shore station via satellite. The data will be integrated into the global seismographic network of 
broadband and very long period seismometers called "Project IDA" (International Deployment of Accelerometers). The data coordinated through this system has helped scientists better understand earthquakes and Earth's interior structure for decades.

The military is part of this vision. Naval applications could utilize constellations of wave glider based sensors that could deploy into an area of operation on their own power, by mother ships or submarines. Future versions could also be air-dropped from aircraft for quick reaction. Typical missions could range from anti-submarine and counter-mine operations, to persistent surveillance of strategic hotspots in littoral areas. The military variant will be based on the same propulsion principle of the wave glider, with specific customization for the military. Communications gateway is another likely application, with the floating robot providing a covert link to and from submerged submarines, employing the wave glider's integral acoustic/satellite relay.

The system already has very low radar reflection, and can be designed to further reduce its reflective and electromagnetic signature, or even be submerged for short periods to mask its presence, Other applications could be customized for littoral and homeland security missions, providing persistent surveillance at sea, supporting port, coastal or offshore installation security, as well as anti-mine and anti-torpedo defense. On such missions wave glider robots could carry radar, RF, visual and acoustic sensing integrated with Automatic Identification Systems (AIS) to perform target detection, identification and tracking.

\section{POTENTIAL CHALLENGES}

The first generation of UGs was quite similar in their physical and functional objectives. They transverse the ocean in a saw-tooth profile, which is well-suited for both vertical and horizontal observations in the water column [42]. Currently, the efforts have focused on improving the propulsive efficiency of these gliders even further. One way to increase propulsive efficiency is to harvest the energy needed for buoyancy change from the thermo cline of the ocean. The Slocum thermal glider is once such glider developed based on this concept [43]. Another way of improving the propulsive efficiency is through design optimization, resulting in a newer type of blended wing-body glider.

Another example is wave glider, which harvests energy from the waves and sun. It has two main bodies, one that float on the sea and other submerged glider. Both are connected via a tether. The glider moves forward by converting ocean wave energy into forward thrust, like the forward motion of an airplane.

Existing underwater gliders face a number of challenges in term of their operational depth, payload capacity, working range and endurance [44]. Specifically:

- The existing buoyancy control mechanism has limitation to work at higher depths because of pressure increases at increasing depth.

- The low strength to weight ratio to enable these gliders to work at greater depths.

- Thermal gliders are less efficiency because of low thermal gradients at various depths of the sea. 
- The hydrodynamic shapes of hull do not support higher payloads at deeper depths.

There are many types of underwater gliders with different capacity of payload delivery and operational depths. These vehicles may potentially be a low energy cost alternative to existing underwater vehicles that are currently being used for subsea installations and maintenance [45].

\section{CONCLUSION}

Autonomous underwater vehicles are now being marketed as robust commercial vehicles for many industries, and of these vehicles underwater gliders are becoming the new tool for oceanographers. Gliders are one of the technological developments that are changing the way to observe the ocean and it is very exciting for us to be at the forefront of the application in ocean and climate science. This paper presents a survey of recent developments in underwater robotics, and on the current hot topic research and technological issues.

After discussing the various stages of $\mathrm{AUV}_{\mathrm{s}}$ and under water gliders development, it can be concluded that the wave glider offers a cheaper, more economical, environmentally sound method of monitoring the seas compared to other AUVs. Wave glider is fit to replace many AUVs for a variety of applications. It could be used for intelligence, surveillance, monitoring exclusive economic zones for fishing and other economic resources that are very important to coastal countries. Wave glider does away with the large crews required for monitoring, cutting down the costs substantially, has a variety of applications in the commercial sector also can be used to find and research resources and fisheries.

Wave glider employs a multi-patented design that allows it to cost-effectively collect and transmit data gathered during yearlong missions, over distances of thousands of miles or while holding station. Wave glider helps us address the biggest challenges our world faces, including global climate change, national security, hurricane \& tsunami warning and offshore energy \& resource management.

At the very least, we hope to show that the progress in underwater robotics is catching up with the capabilities of the other robotic fields in producing original, differentiated, designs and systems tailored to the specific application needs, getting closer and closer to the autonomy expected by cognitive systems. Underwater robots are well on their way to take part in our every-day lives and activities.

The recommendations for a better future of the underwater gliders can be concluded in increasing the interest of ship owners and designers in the robotics market especially for the wave glider to replace many AUVs for a variety of applications and promote its use on a large scale, finally new research programs are needed to find efficient solutions for the problems associated with the applications of wave glider. 


\section{ACKNOWLEDGEMENTS}

The author would like to thank the College of Shipbuilding Engineering in Harbin Engineering University - China for their support in different tasks during the research that has led to this paper.

\section{REFERENCES}

[1] Q. B. Yong Bai, Ed., Subsea Engineering Handbook. Gulf Professional, (2012).

[2] M. F. bin Ibrahim, M. Ovinis, and K. bin Shehabuddeen, "An Underwater Glider for Subsea Intervention: A Technical Feasibility Study," AMM, vol. 393, pp. 561-566,( 2013).

[3] Caccia M.; Bono R.; Bruzzone G., Veruggio G. (2000). Unmanned underwater vehicles for scientific applications and robotics research: The ROMEO project. Marine Technology Society Journal, vol. 34/2, pp.3-17.

[4] Correia L. and Steiger-Garcao A. (1991). An AUV architecture and world model. $5^{\text {th }}$ International. Conf. on Advanced Robotics, vol 2, pages 1315-1320, Pisa, Italy.

[5] G. Griffiths, C. Jones, J. Ferguson, and N. Bose, "Undersea gliders," Journal of OT, vol. 2, pp. 64-75, (2007).

[6] Hine, Roger G., Derek L. Hine, Joseph D. Rizzi, Kurt A.F Kiesow, Robert Burcham, and William A. Stutz (2007). Wave Power. Liquid Robotics Inc., assignee. Patent 7371136.

[7] Bellingham J.G.; Goudey C.A.; Consi T.R.; Bales J.W. (1994). A second generation survey AUV. IEEE Symposium. Autonomous Underwater Vehicle Technology. P 148-155, Cambridge

[8] AUV Laboratory at MIT Sea Grant, History (2012) . Web. 22 Dec. 2015.

[9] Graver, J.G. (2005). Underwater Gliders: Dynamics, Control and Design. Dissertation, Princeton University, Department of Mechanical and Aerospace Engineering.

[10] Odyssey IV Robot Submarine by MIT, Geekie Gadgets (2008). Latest Technology. Web. 24 Dec. 2015.

[11] Alves, J.; Oliveira, P.; Oliveira, R.; Pascoal, A.; Rufino, M.; Sebastiao, L.; Silvestre, C. (2006). Vehicle and mission control of the DELFIM autonomous surface craft. IEEE $14^{\text {th }}$ Mediterranean Conf. Control Automation, Ancona.

[12] Leonessa, A.; J. Mandello, J.; Morel, Y.; Vidal, M. (2003), Design of a small, multipurpose, autonomous surface vessel. IEEE OCEANS'03 Conf., San Diego.

[13] Mies, G. (2010). Military robots of the present and the future, AARMS vol. 9/1, pp.125-137.

[14] Bash, J.F. (2008). New ship technology and design. J. Marine Tech. Society. Vol. 42/1, pp.21-25.

[15] Bellingham, J.G.; Zhang Y. (2009). Autonomous ocean sampling network-II (AOSN-II): Integration and demonstration of observation and modeling (Final Report).

[16] Leonard, N.E.; Paley, D.A, Davis R.E.; Fratantoni, D.M.; Lekien, F.; Zhang, F. (2010), Coordinated control of an underwater glider fleet in an adaptive ocean sampling field experiment in Monterey Bay. Journal of Field Robotics 27/6, pp.718-740 
[17] The Wave Glider Technology (2012). Ocean Robots Journey Across Pacific Ocean for New Scientific Discoveries. Web. 24 Dec. 2015

[18] T. Ura, "Free Swimming Vehicle 'PTEROA' for Deep Sea Survey," Proc. ROV'89, pp. 263-268, (1989)

[19] K. Kawaguchi, Y. Tomoda, H. Kobayashi, and T. Ura, "Development and sea trials of a shuttle type AUV ALBAC," in International symposium on Unmanned Untethered Submersible Technology, (1993).

[20] D. L. Rudnick, R. E. Davis, C. C. Eriksen, D. M. Fratantoni, and M. J. Perry, "Underwater gliders for ocean research," Marine Technology Society Journal, vol. 38, pp. 73-84, (2004)

[21] D. C. Webb, P. J. Simonetti, and C. P. Jones, "SLOCUM: An underwater glider propelled by environmental energy," Oceanic Engineering, IEEE Journal of, vol. 26, pp. 447-452,( 2001).

[22] J. Sherman, R. E. Davis, W. Owens, and J. Valdes, "The autonomous underwater glider," Oceanic Engineering, IEEE Journal of, vol. 26, pp. 437-446, (2001).

[23] Webb, D. C., Simonetti, P. J., Jones, C.P. (2001). SLOCUM: an underwater glider propelled by environmental energy. IEEE J. Oceanic Engineering, Volume 26, Issue 4, pp. $447-452$.

[24] Sherman, J., Davis, R. E., Owens, W. B., and Valdes, J. (2001). The autonomous underwater glider Spray, IEEE Journal of Oceanic Engineering. Volume 26, Issue 4, pp. 437-446.

[25] Griffiths, G., Ed., Davis, R. E., C. C. Eriksen, and C. P. Jones, (2002). Autonomous buoyancy-driven underwater gliders, In: Technology and Applications of Autonomous Underwater Vehicles Taylor and Francis, London.

[26] H. C. Woithe, I. Chigirev, D. Aragon, M. Iqbal, Y. Shames, S. Glenn, et al., "Slocum glider energy measurement and simulation infrastructure," in OCEANS 2010 (2010), pp. 1-8.

[27] J. Borchsenius and S. Pinder, "Underwater glider propulsion using chemical hydrides," in OCEANS 2010 IEEE - Sydney, (2010), pp. 1-8.

[28] C. C. Eriksen, T. J. Osse, R. D. Light, T. Wen, T. W. Lehman, P. L. Sabin, et al., "Seaglider: A long-range autonomous underwater vehicle for oceanographic research," Oceanic Engineering, IEEE Journal of, vol. 26, pp. 424-436, (2001).

[29] G. Griffiths and I. Edwards, "AUVs: designing and operating next generation vehicles," Elsevier Oceanography Series, vol. 69, pp. 229-236, (2003).

[30] Eriksen, C.C.; Osse, T.J.; Light, R.D.; Wen, T.; Lehman, T.W.; Sabin, P.L.; Ballard, J.W.; Chiodi, A.M. (2001). Seaglider: A long range autonomous underwater vehicle for oceanographic research, IEEE J. Oceanic Engin., Volume 26, Issue 4, pp. 424-436.

[31] T. J. Osse and C. C. Eriksen, "The deepglider: a full ocean depth glider for oceanographic research," in OCEANS (2007), pp. 1-12

[32] ONR (2006). Liberdade XRAY Advanced Underwater Glider, ONR press release, retrieved on 15 Sept. 2008. <https://www.onr.navy.mil/media/extra/fact_sheets/ advanced_underwater_glider.

[33] N. Mahmoudian, J. Geisert, and C. Woolsey, "Dynamics and control of underwater gliders I: Steady motions," Technical Report, Virginia Polytechnic Institute and State University (2009).

[34] J. G. Graver, "Underwater gliders: Dynamics, control and design," Citeseer, (2005). 
[35] D'Spain, G.L.; Zimmerman, R.; Jenkins, S.A.; Luby, J.C.; and Brodsky, P. (2007). Underwater acoustic measurements with a flying wing glider. J. Acoust. Soc. Am., Vol. 121, No. 5, Pt. 2, pp. 3107.

[36] W. P. Barker, "An Analysis of Undersea Glider Architectures and an Assessment of Undersea Glider Integration into Undersea Applications," Monterey, California. Naval Postgraduate School, (2012).

[37] Hyakudome, T.; Yoshida, H.; Ishibashi, S.; Sawa, T.; (2011). Development of advanced Lithium-ion battery for underwater vehicle. IEEE Underwater Technology Symposium; Tokyo.

[38] Blidberg,.D.R.; Mupparapu, S.; Chappell, S.; Komerska, R.; (2005). The SAUV II (solar powered AUV) test results 2004, IEEE Oceans '2005, vol 1, p545-550, France.

[39] Liquid Robotics Fleet of Self-propelled, Solar-powered, Ocean- Going Robots (2011). Web. 24 Dec. 2015

[40] X. Wang, J. Shang, Z. Luo, L. Tang, X. Zhang, and J. Li, "Reviews of power systems and environmental energy conversion for unmanned underwater vehicles," Renewable and Sustainable Energy Reviews, vol. 16, pp. 1958-1970, 5// (2012).

[41] Frolov, S.; Bellingham, J.; Anderson, W.; Hine, G (2011). Wave Glider - A platform for persistent monitoring of algal blooms. IEEE Oceans'11, Kona

[42] S. A. Jenkins, D. E. Humphreys, J. Sherman, J. Osse, C. Jones, N. Leonard, et al., "Underwater glider system study," (2003).

[43] R. E. Davis, C. C. Eriksen, and C. P. Jones, "Autonomous buoyancy-driven underwater gliders," Taylor and Francis, London, (2002), pp. 37-58.

[44] Yamamoto, I. (2006). Research and development of past, present, and future AUV technologies, Master class in AUV Technology for Polar Science, National Oceanography Centre, Southampton

[45] S. Wood, "Autonomous underwater gliders," Underwater Vehicles, pp. 499-524, (2009) 


\section{FIGURES AND TABLES}

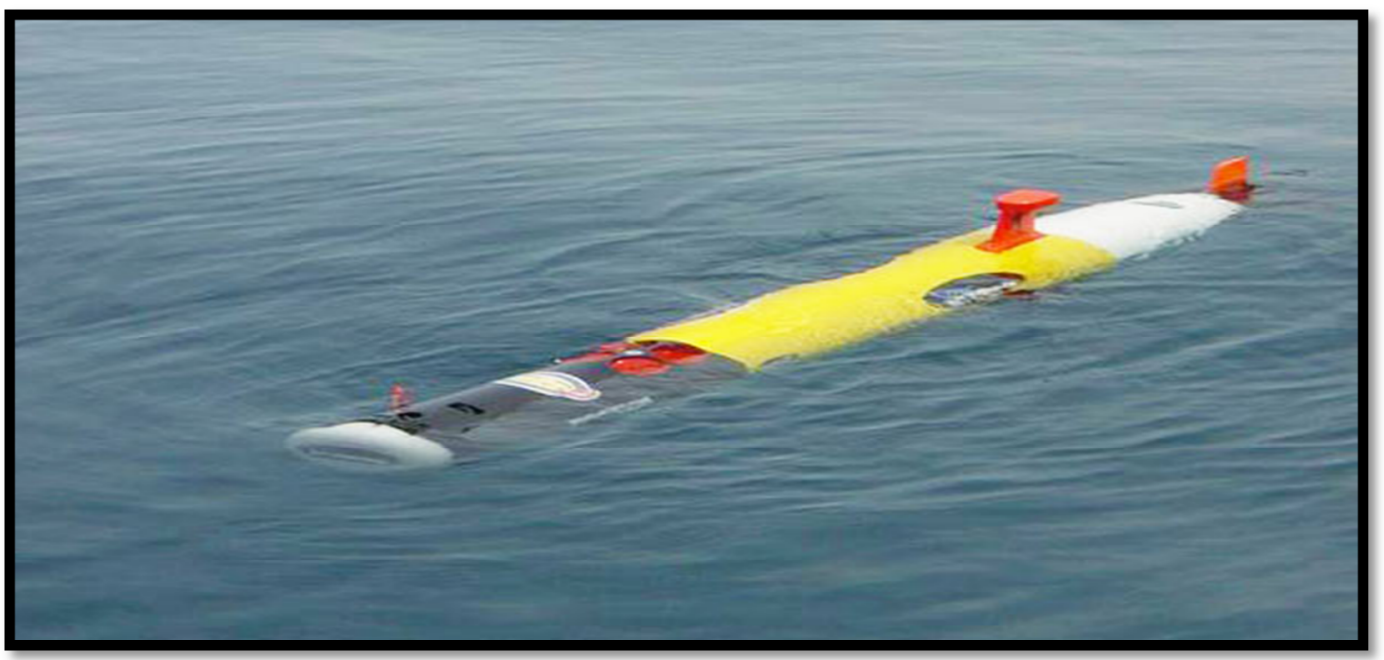

Fig. 1. AUV on mission [3].

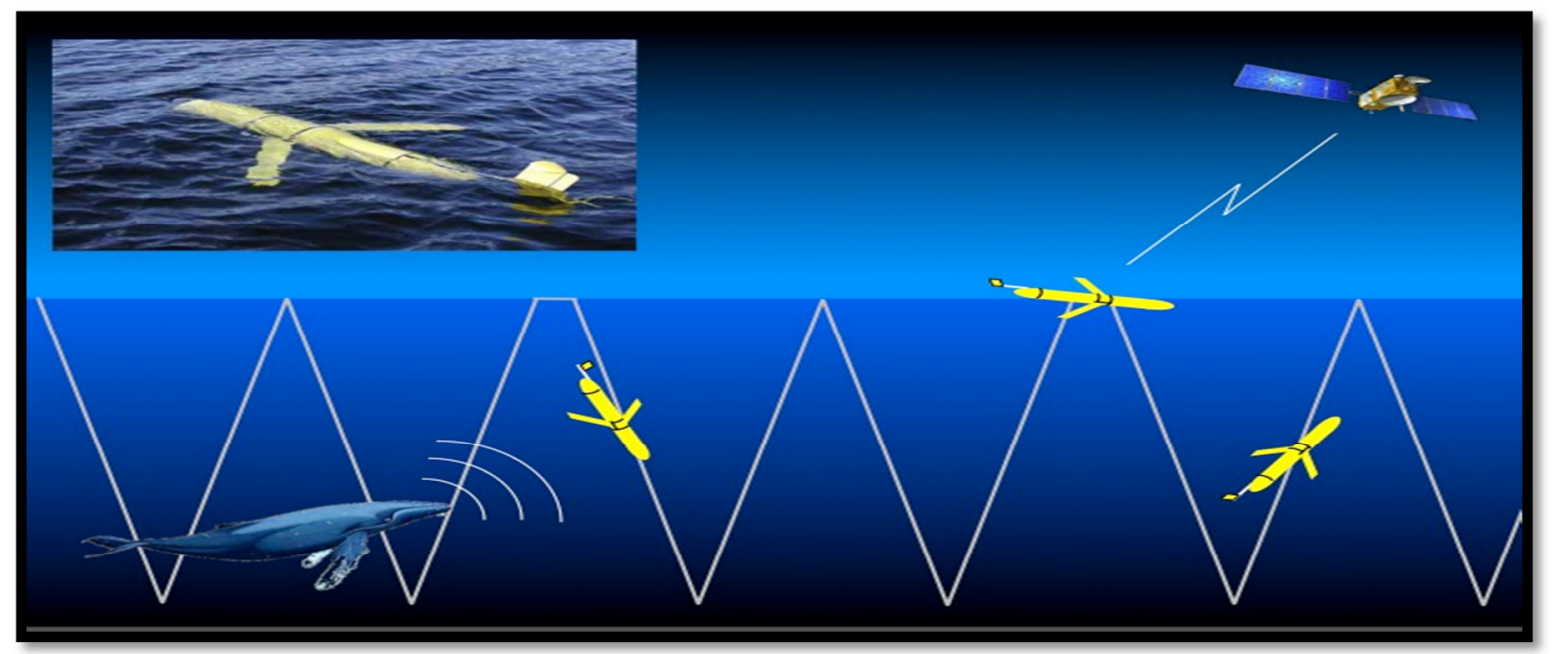

Fig. 2. Underwater glider movement [5].
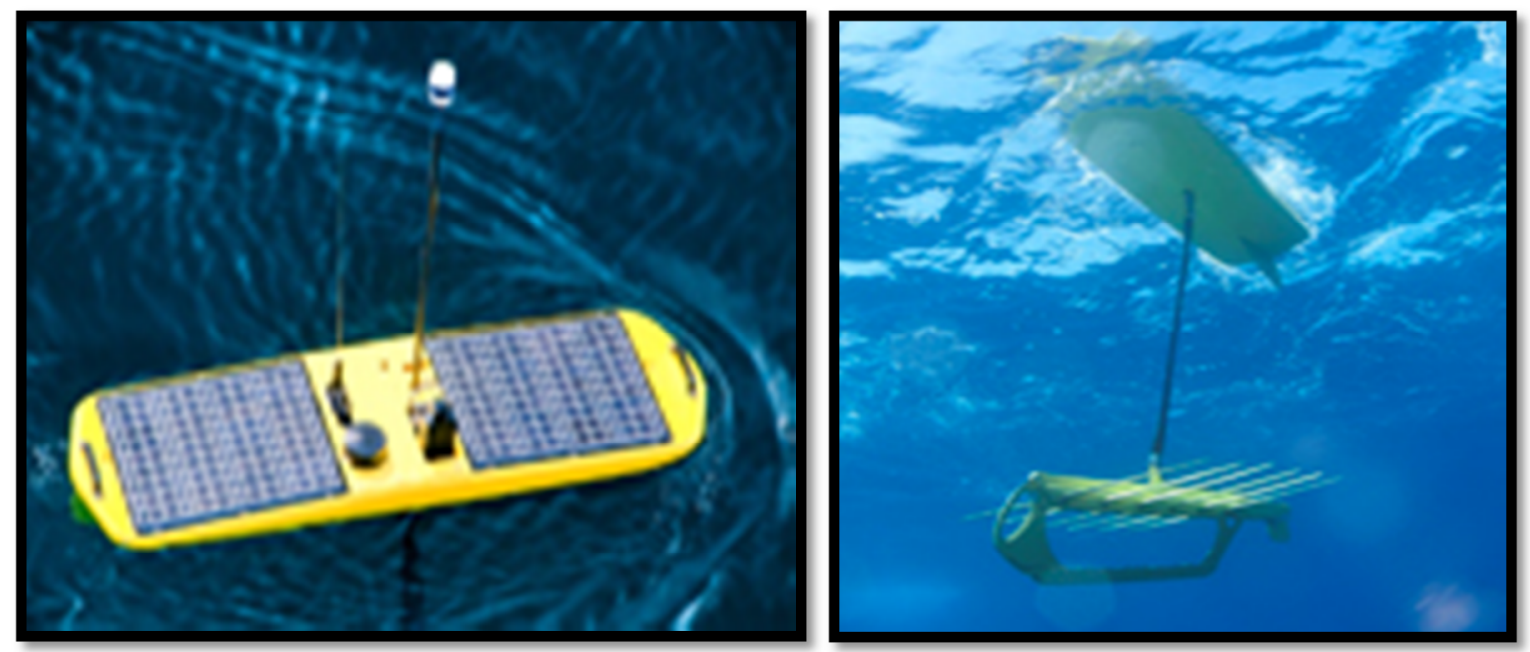

Fig. 3. Wave Glider [6]. 


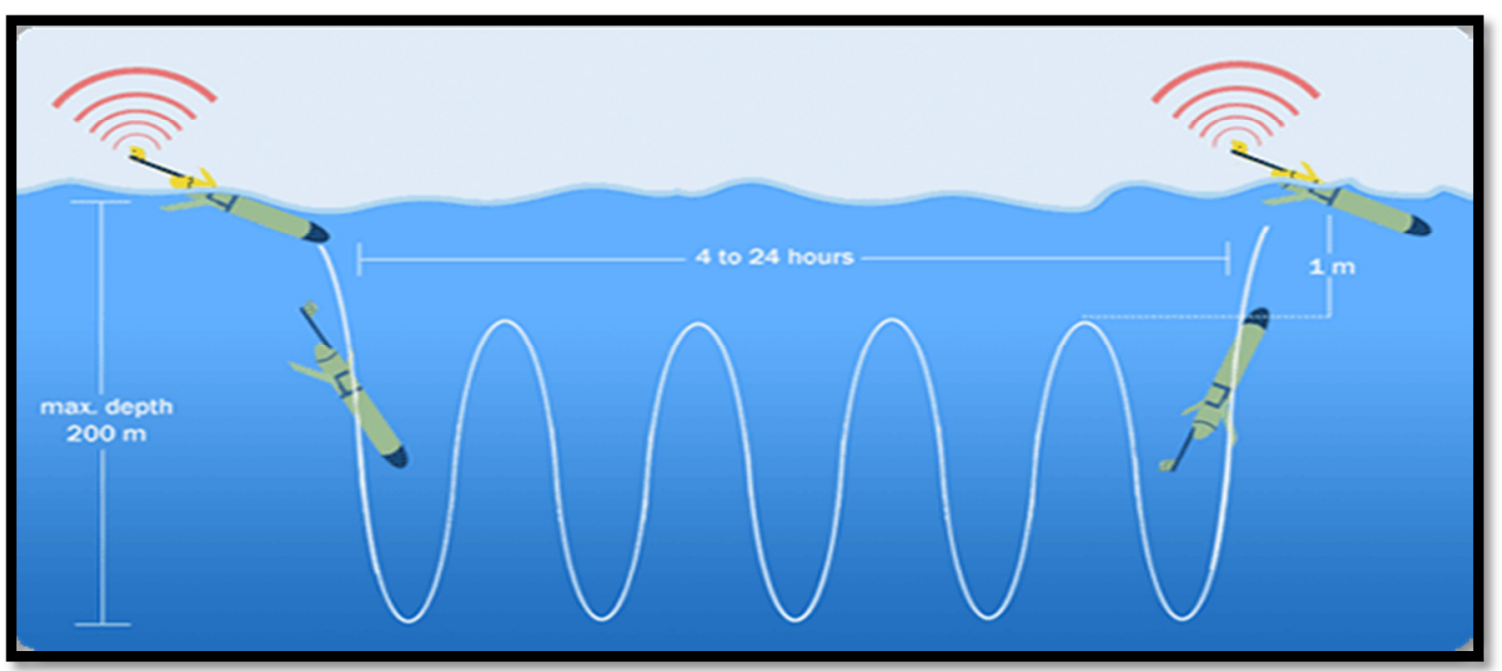

Fig. 4. AUVs communications via satellite [8].

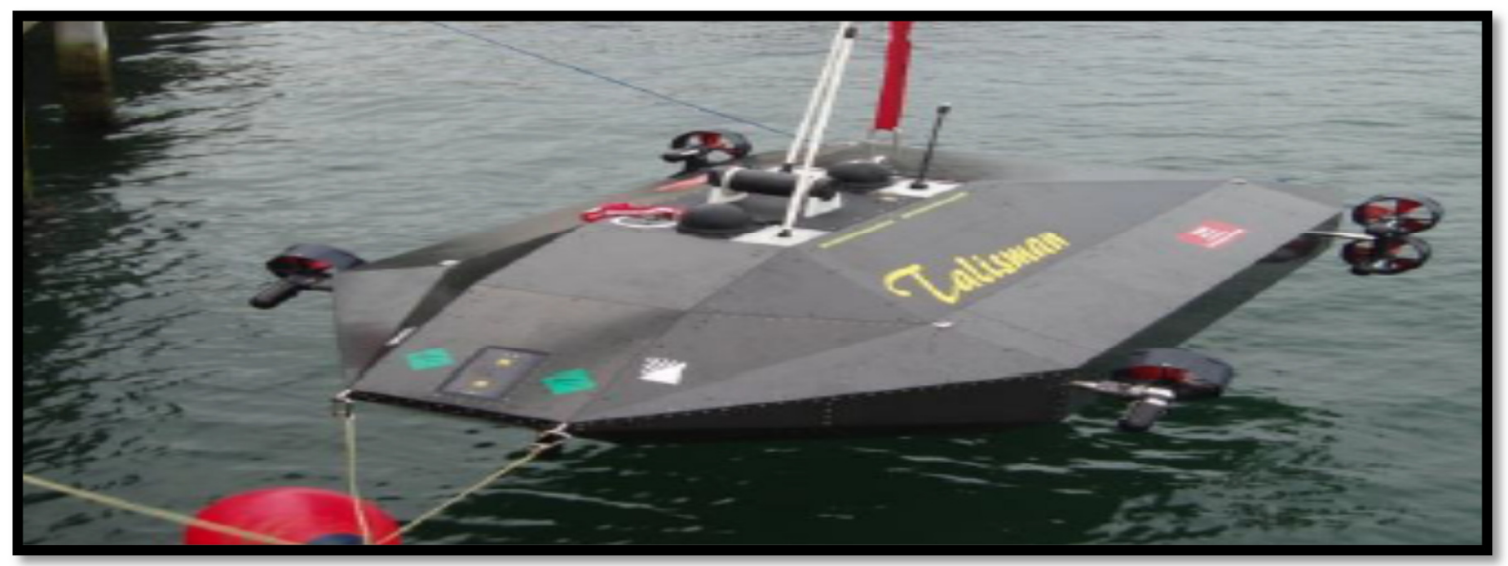

Fig. 5. Military AUV [8].

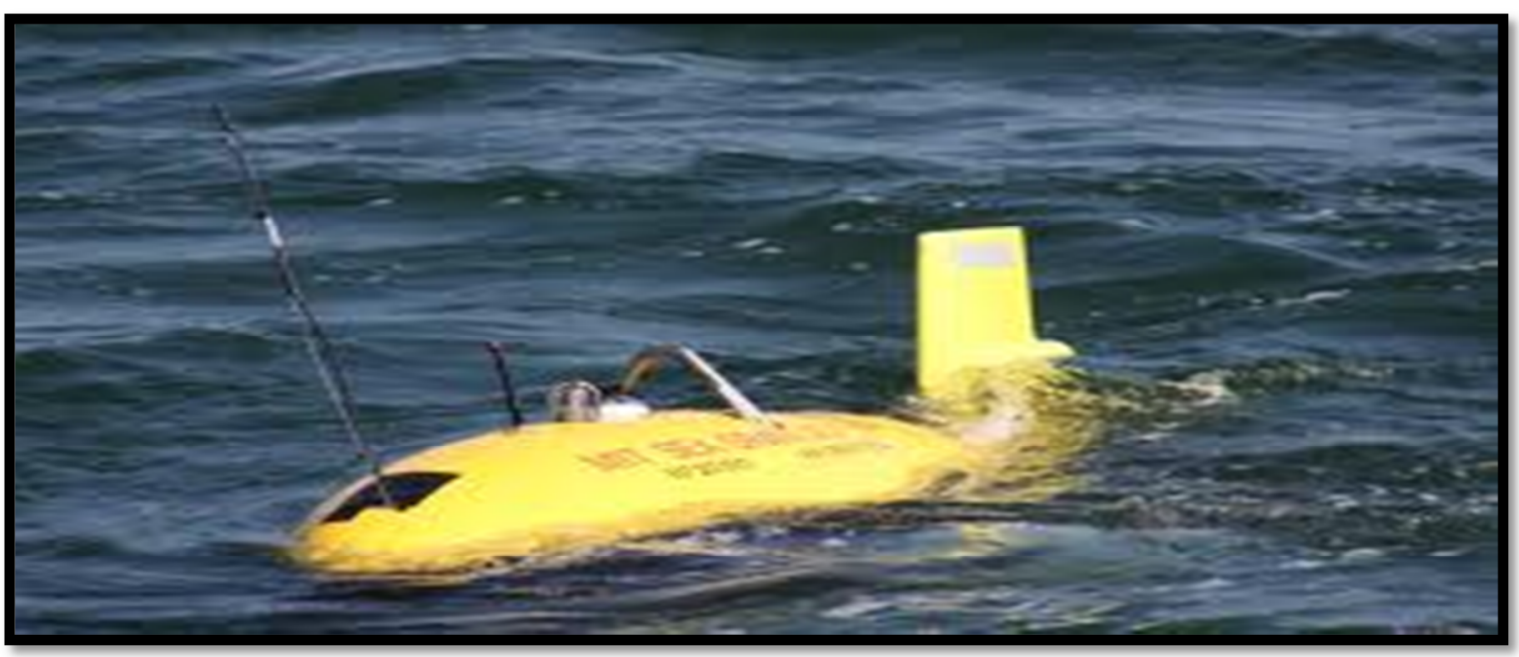

Fig. 6. MIT's Odyssey [10]. 


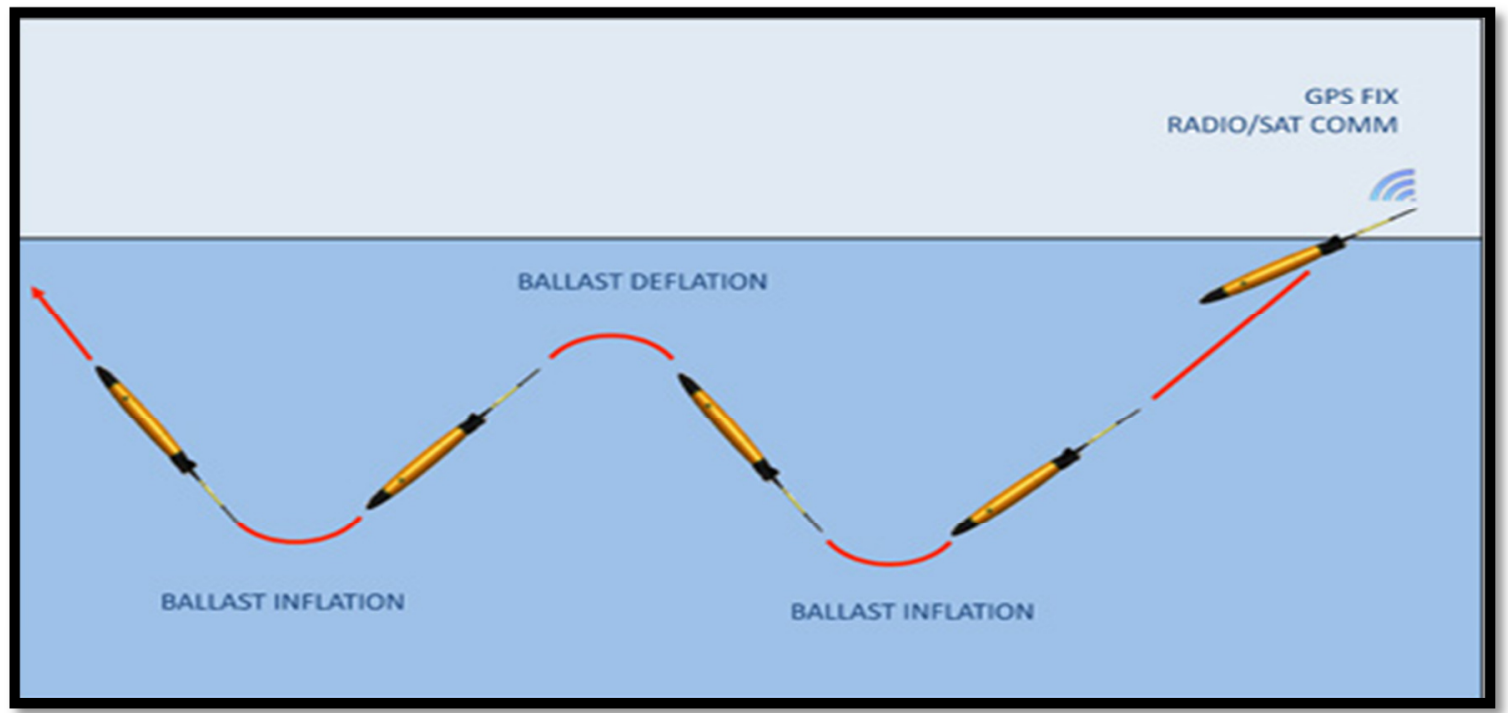

Fig. 7. Ballast variation of AUVs.

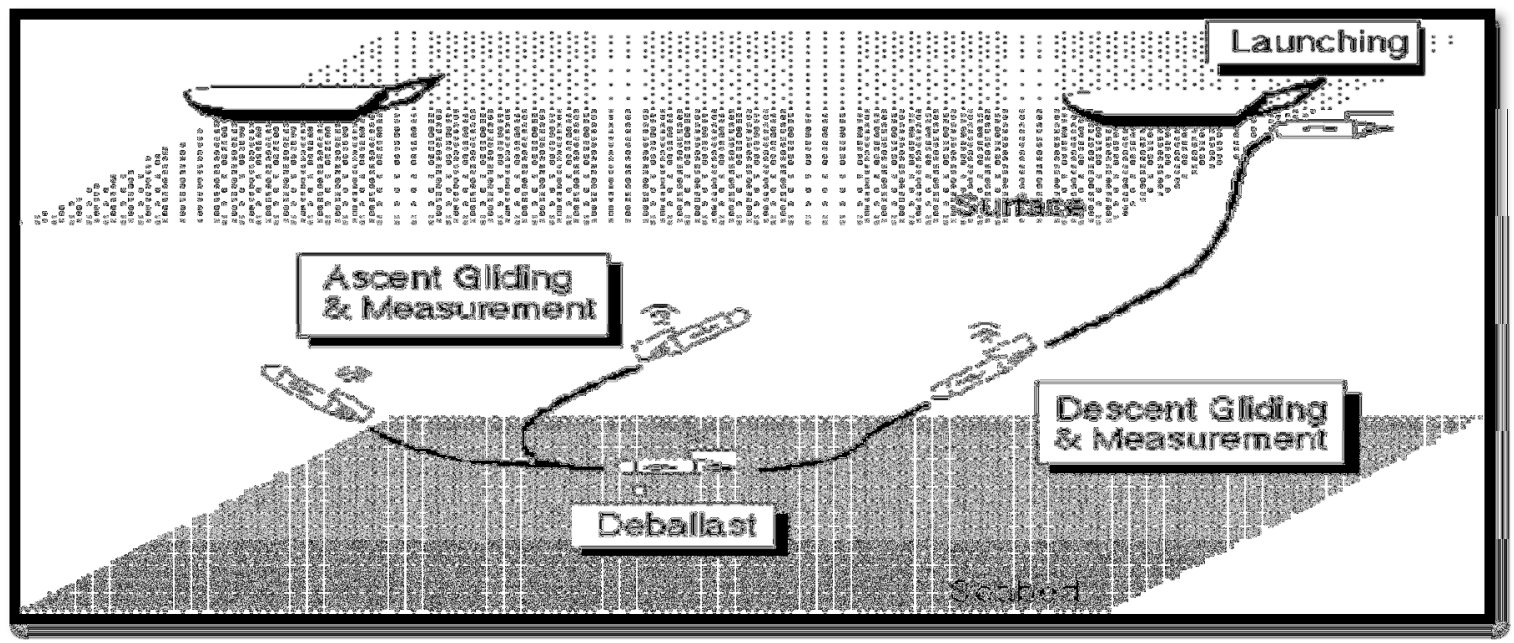

Fig. 8. ALBAC glider movement [18].

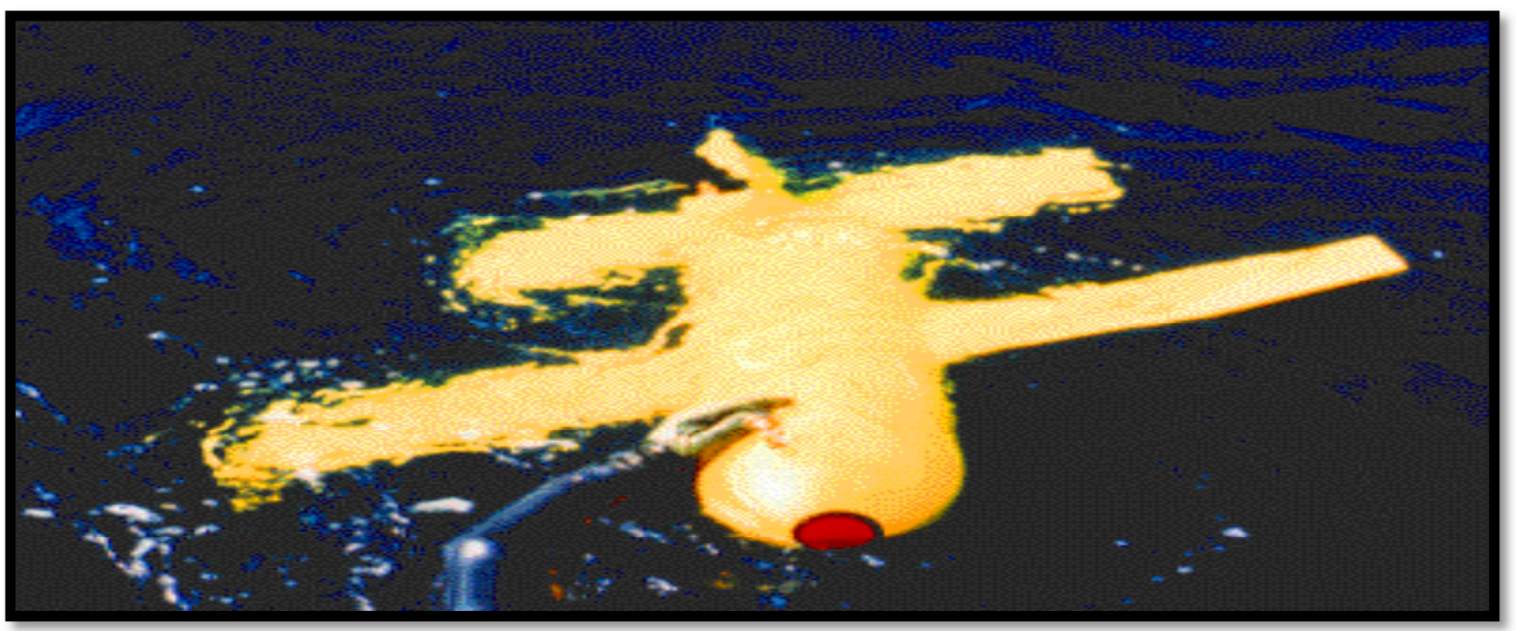

Fig. 9. ALBAC glider [19]. 


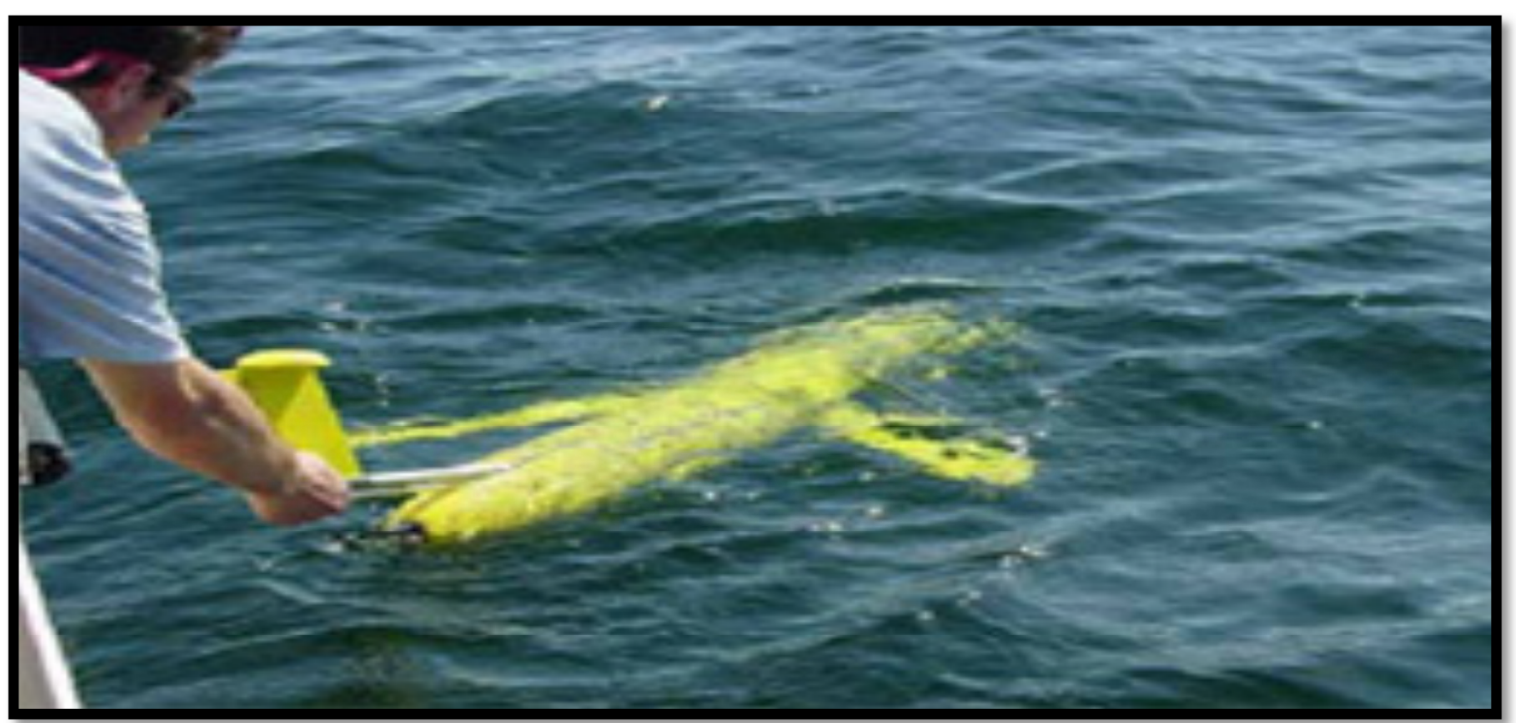

Fig. 10. Slocum glider [20].

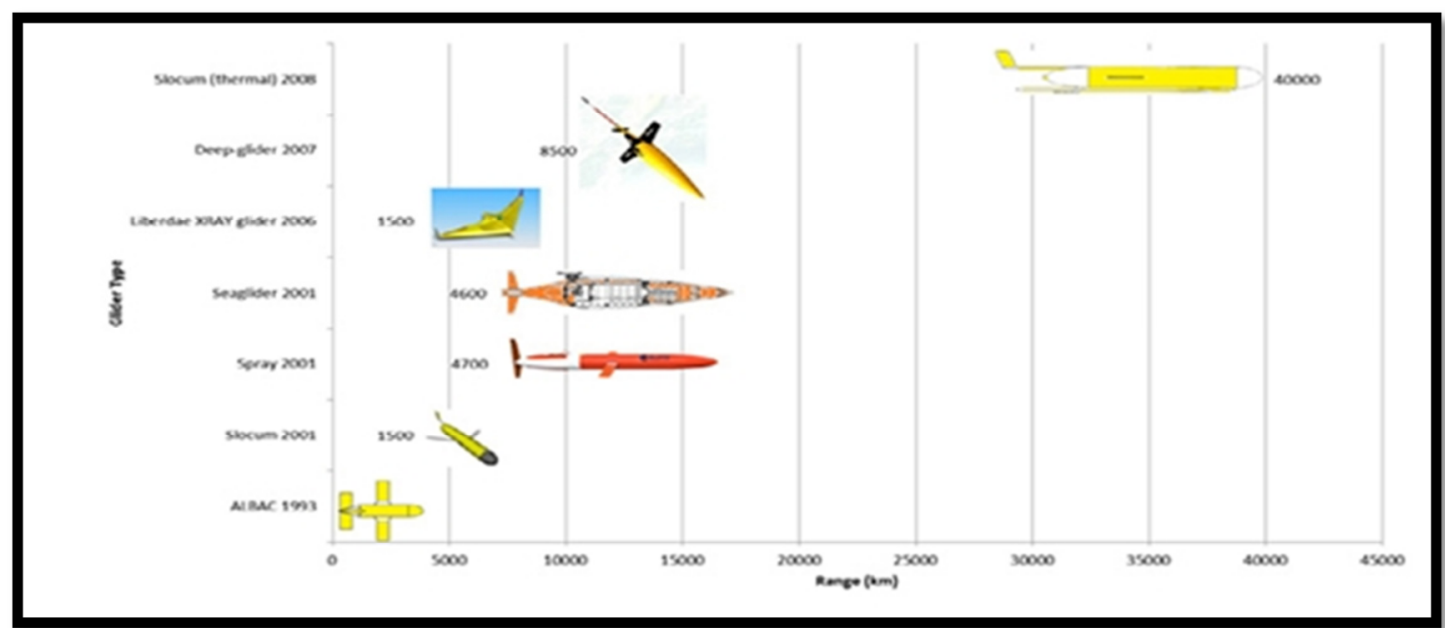

Fig. 11. Comparison of glider range.

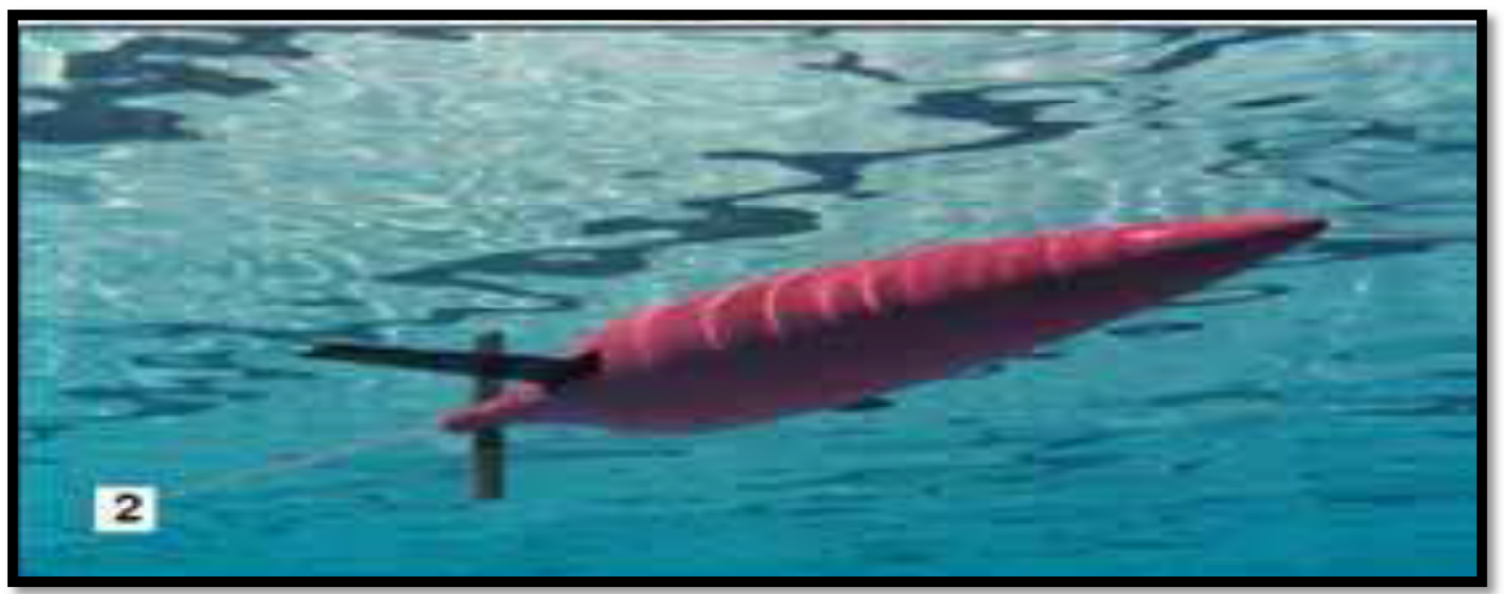

Fig. 12. Sea glider [28]. 


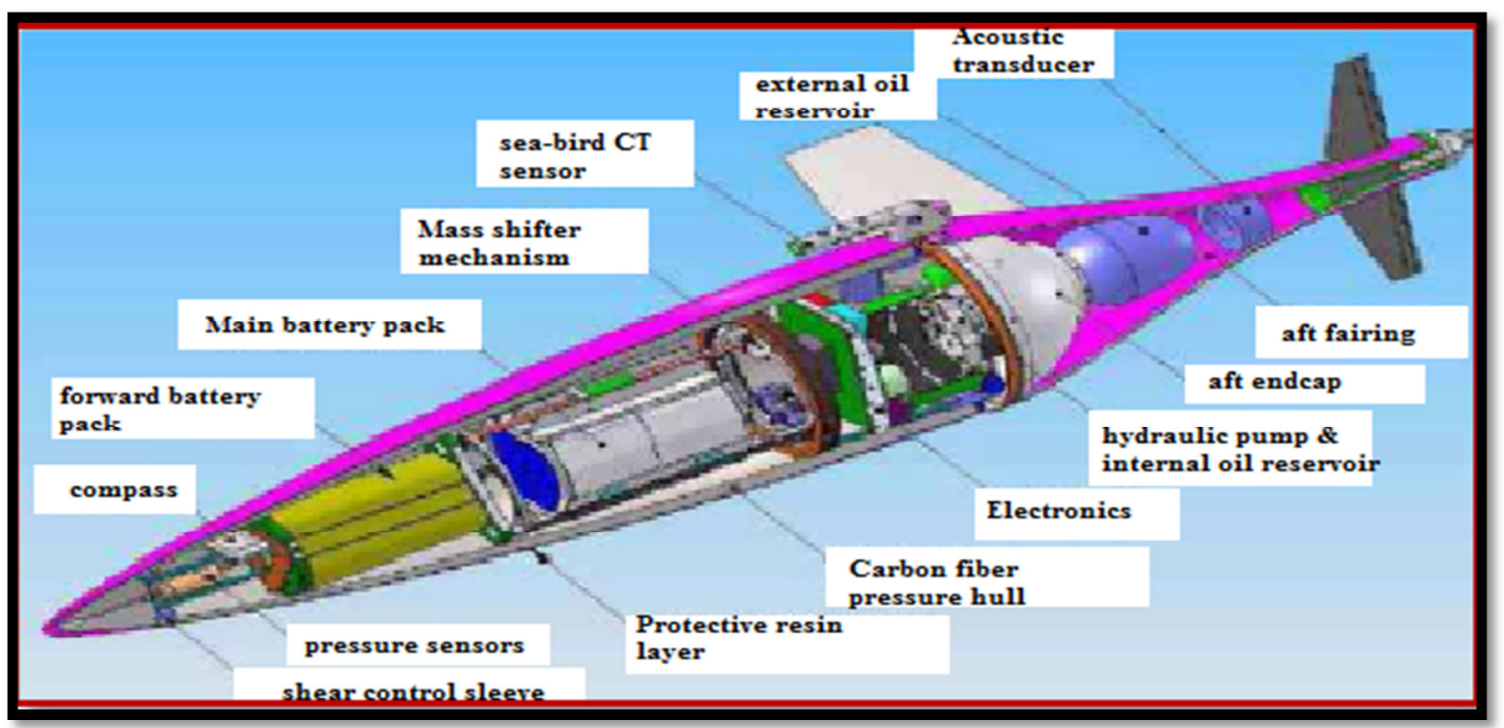

Fig. 13. The deep glider [31].

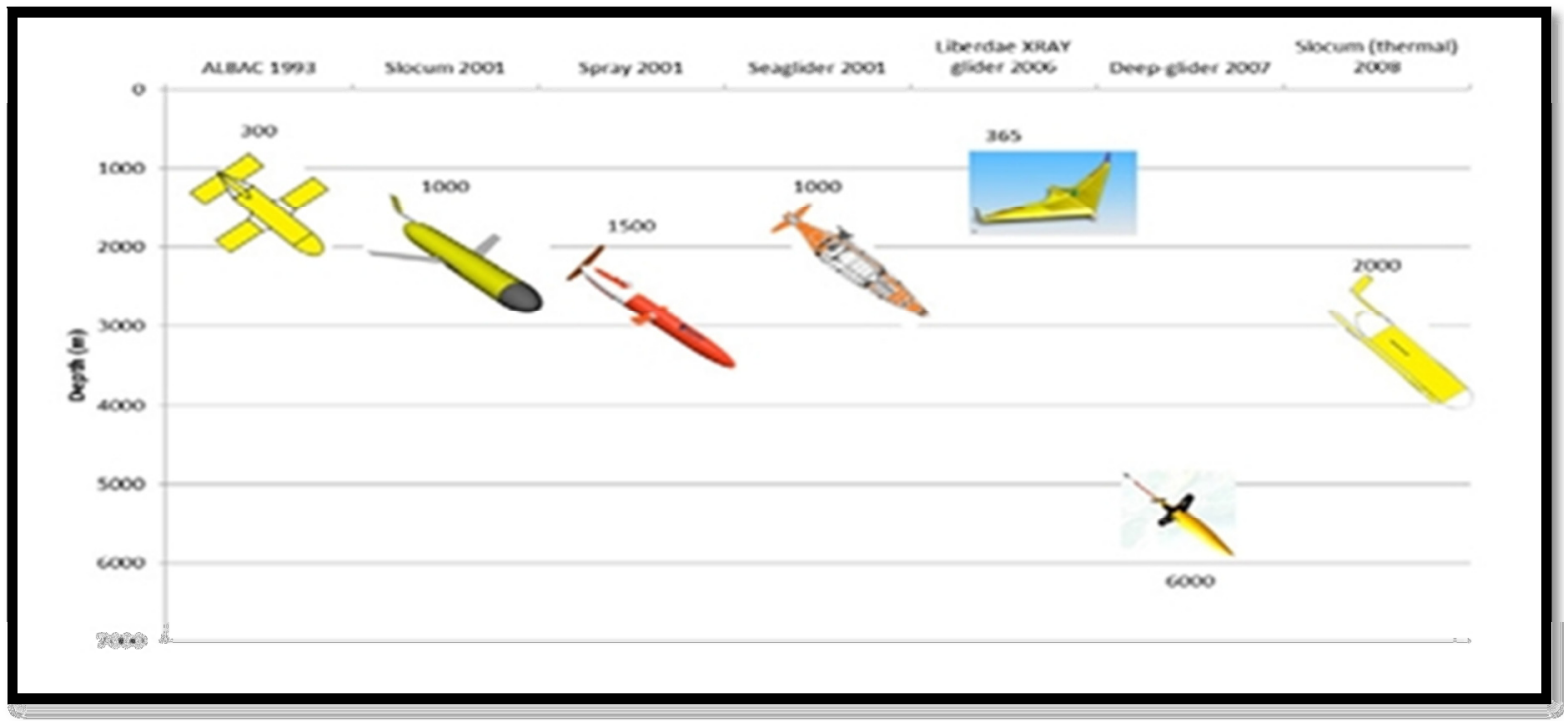

Fig. 14. Comparison of glider depth.

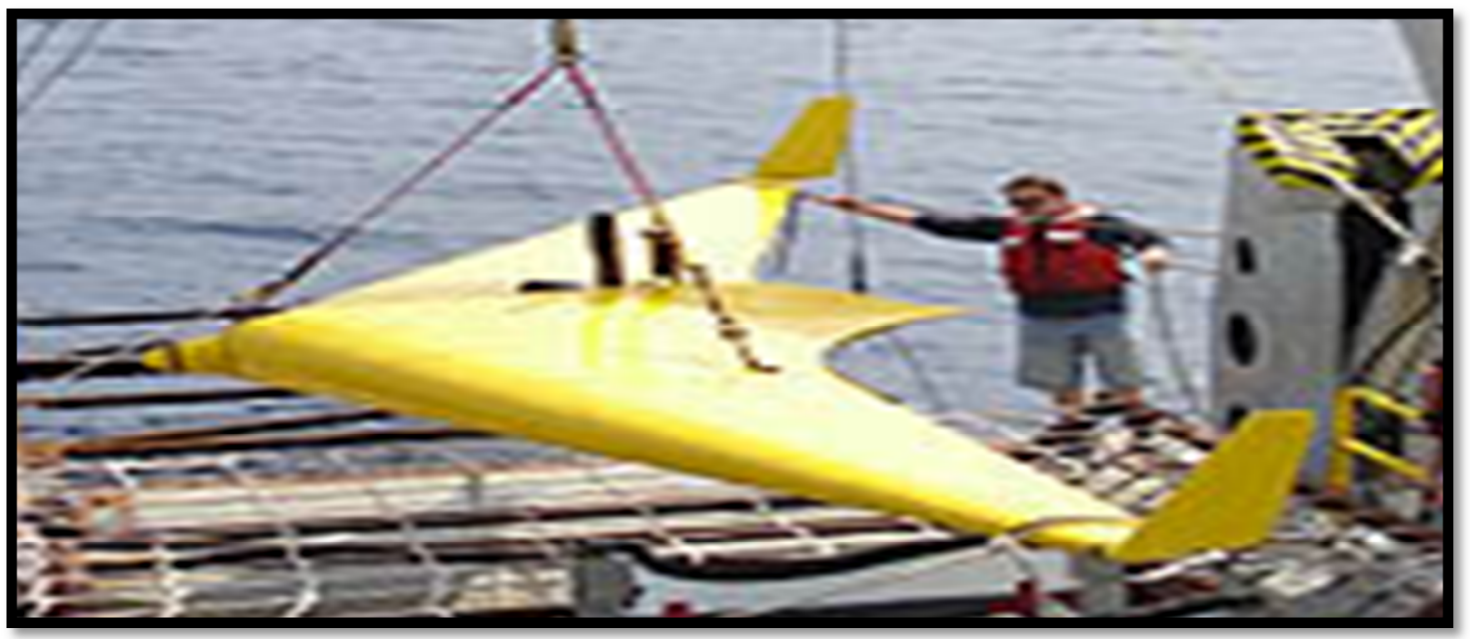

Fig. 15. XRAY Glider [32]. 


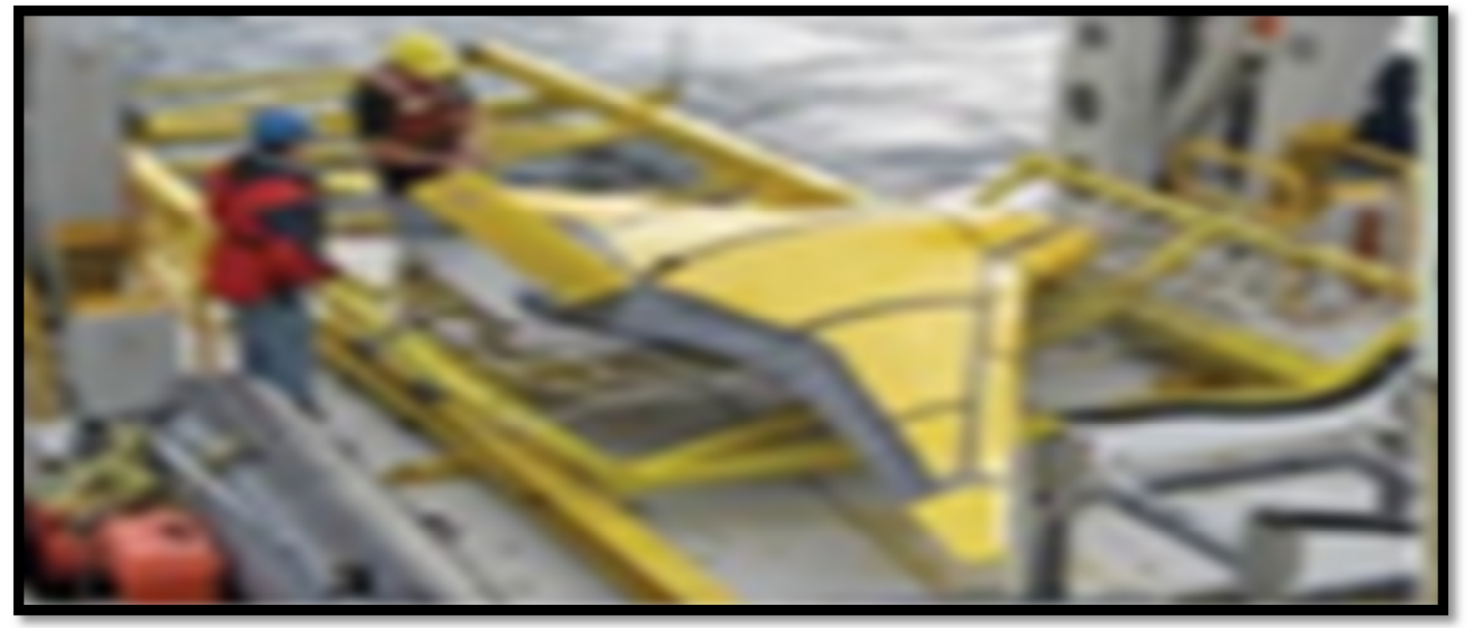

Fig. 16. ZRAY Glider [32].

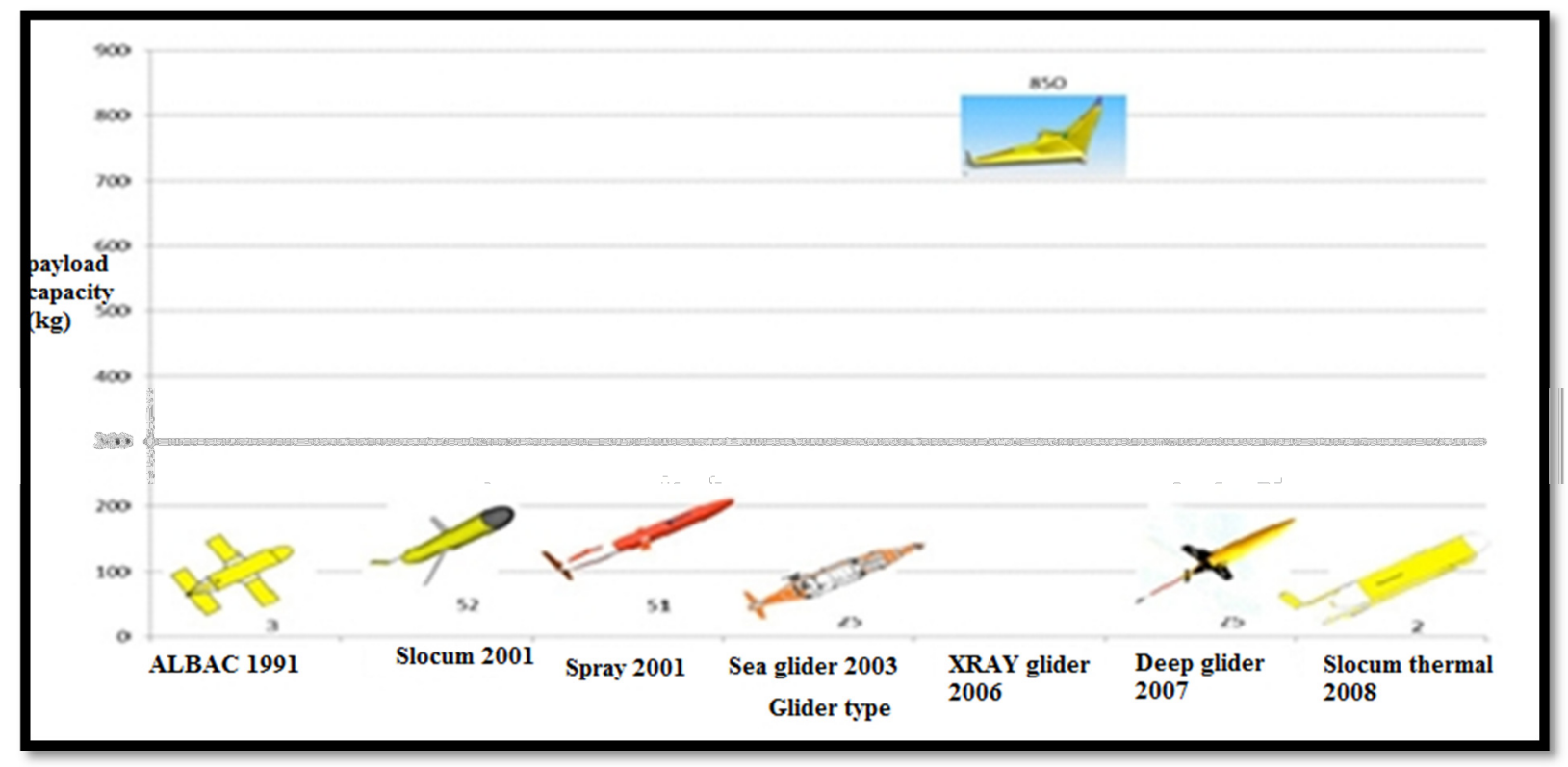

Fig. 17. Comparison of payload.
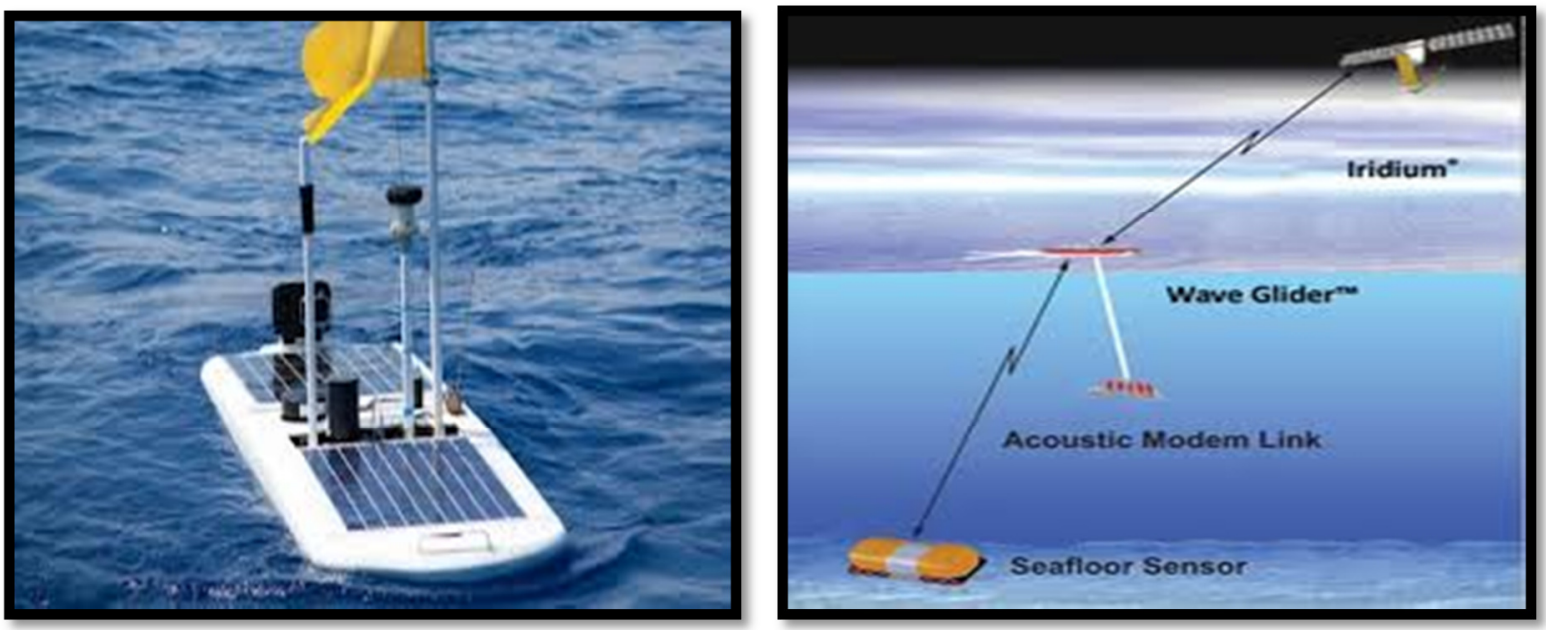

Fig. 18. Wave glider method of travel. 


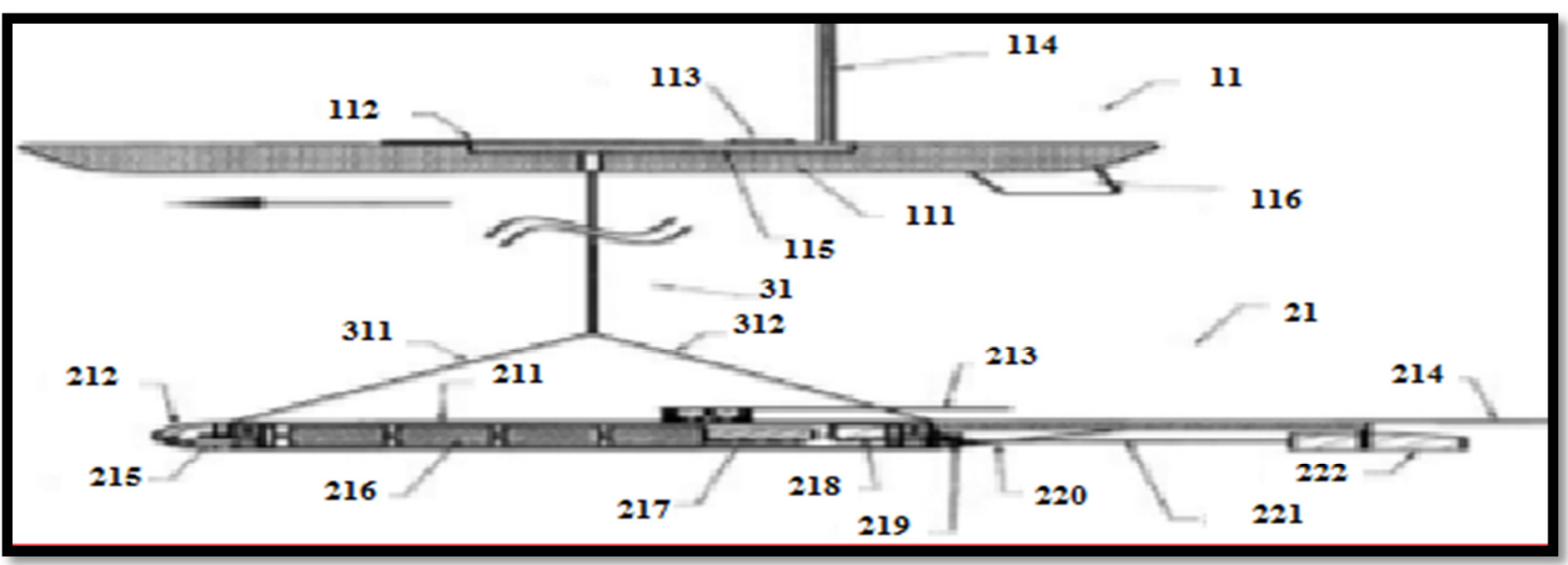

Fig. 19. Basic design patent.

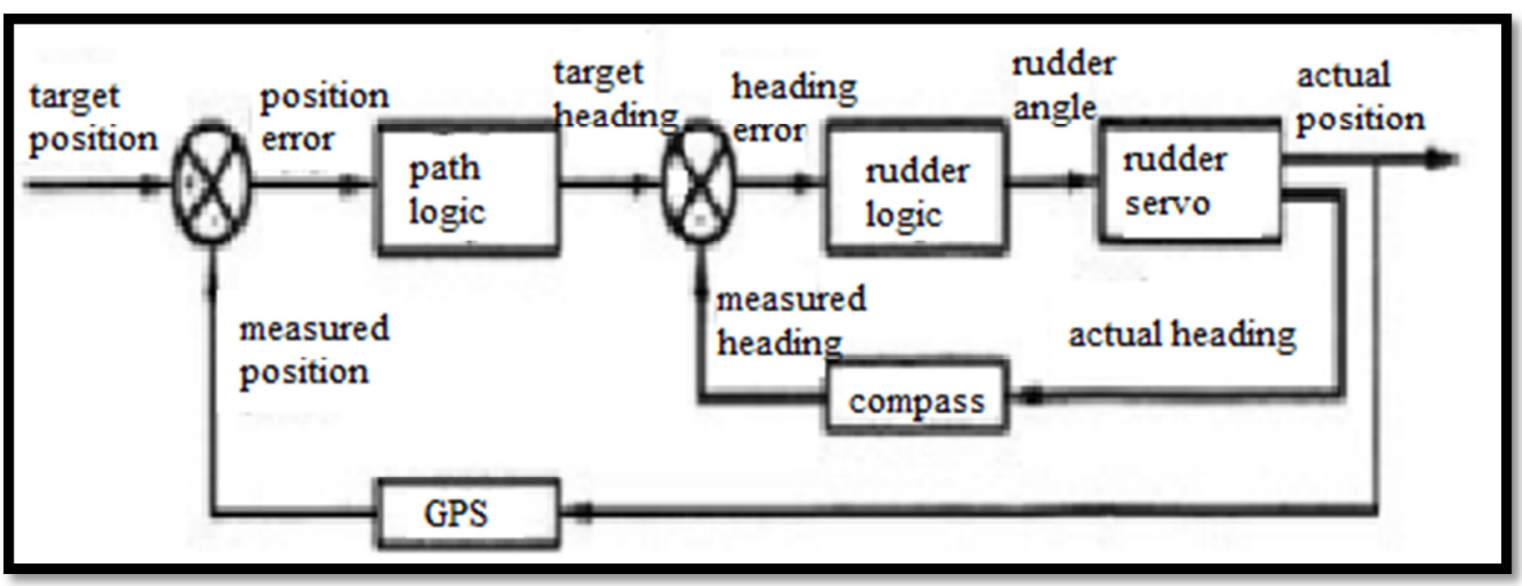

Fig. 20. Autonomous steering setup.

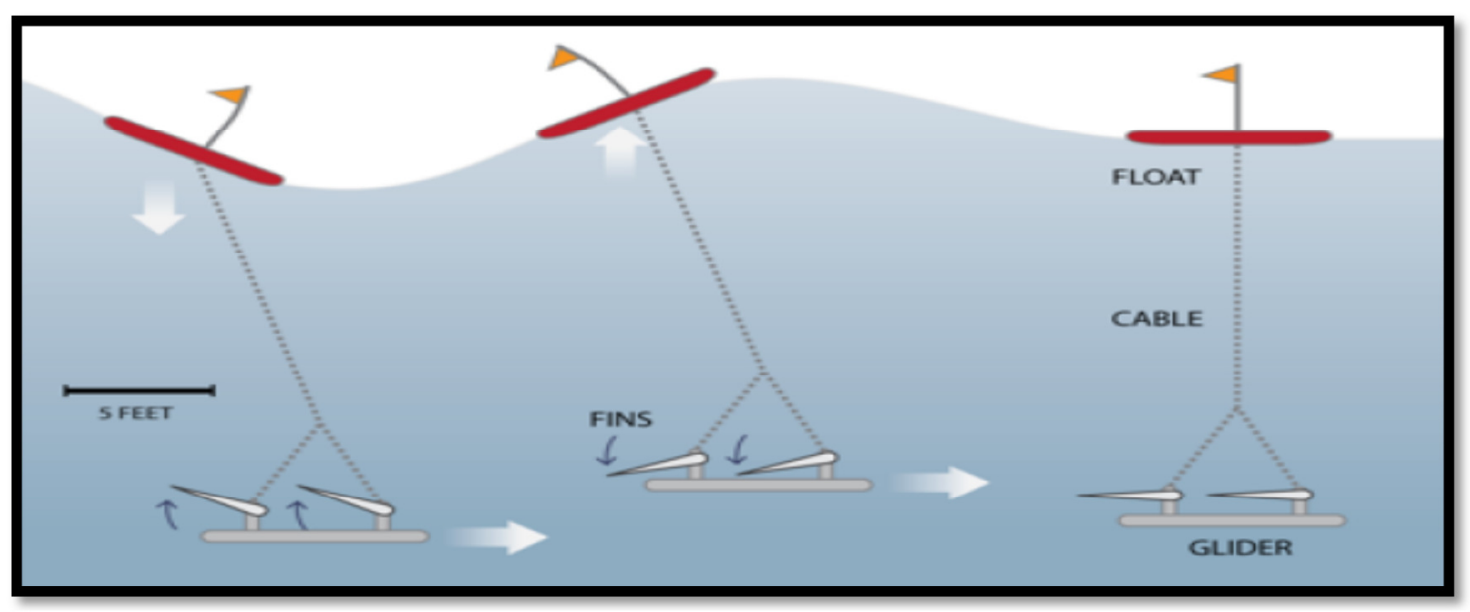

Fig. 21 wave glider method 

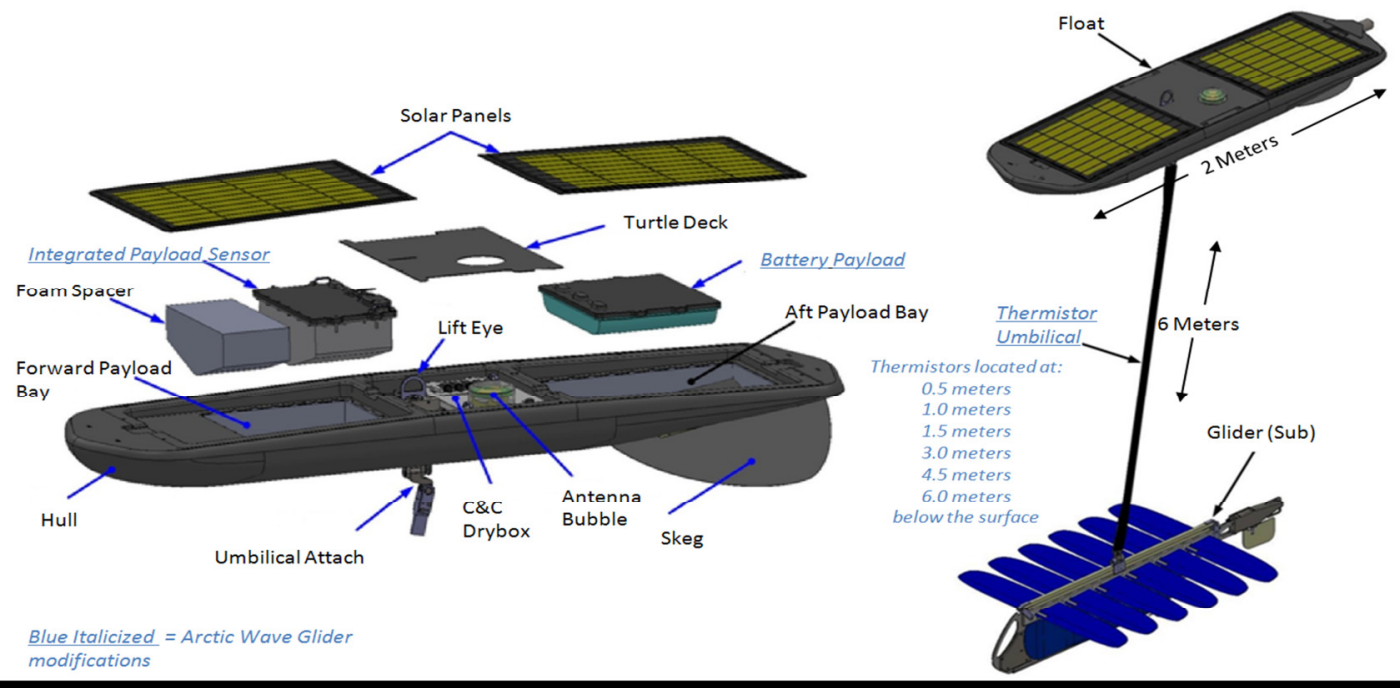

Fig. 22. The breakdown of wave glider structure.

Table 1. Comparison between Spray, Slocum Battery and Slocum Thermal Gliders Specifications.

\begin{tabular}{|c|c|c|c|}
\hline Types & Slocum Battery glider & Slocum Thermal glider & Spray glider \\
\hline Weight & $52 \mathrm{~kg}$ & $60 \mathrm{~kg}$ & $51 \mathrm{~kg}$ \\
\hline Hull diameter & $21.3 \mathrm{~cm}$ & $21.3 \mathrm{~cm}$ & $20 \mathrm{~cm}$ \\
\hline Vehicle length & $1.5 \mathrm{~m}$ & $1.5 \mathrm{~m}$ & $2 \mathrm{~m}$ \\
\hline Wing span & $120 \mathrm{~cm}$ & $120 \mathrm{~cm}$ & $110 \mathrm{~cm}$ \\
\hline Depth range & $\begin{array}{l}\text { 4-200m (coastal model) } \\
-1000 \mathrm{~m}(1 \mathrm{~km} \text { model })\end{array}$ & $4-2000 m$ & $200-1500 \mathrm{~m}$ \\
\hline Payload & 3 to $4 \mathrm{~kg}$ & $2 \mathrm{~kg}$ & $\begin{array}{c}3.5 \text { to } 51.8 \mathrm{~kg} \text { depending on the glide } \\
\text { ratio }\end{array}$ \\
\hline Speed & 0.3 to $0.4 \mathrm{~m} / \mathrm{sec}$ & $0.4 \mathrm{~m} / \mathrm{sec}$ horizontal & $0.25-0.35 \mathrm{~m} / \mathrm{sec}$ horizontal \\
\hline Energy & alkaline batteries & $\begin{array}{l}\text { Thermal engine, } \\
\text { Alkaline batteries }\end{array}$ & $\begin{array}{c}\text { Primary lithium sulfuryl chloride } \\
\text { batteries }\end{array}$ \\
\hline Range & $1500 \mathrm{~km}$ & $40,000 \mathrm{~km}$ & $\begin{array}{c}3500 \text { to } 4700 \mathrm{~km} \text { depending on the glide } \\
\text { ratio }\end{array}$ \\
\hline Navigation & \multicolumn{3}{|c|}{ GPS, and internal dead reckoning, altimeter } \\
\hline $\begin{array}{l}\text { Communication } \\
\mathrm{s}\end{array}$ & \multicolumn{2}{|c|}{ RF modem, Iridium satellite, ARGOS, } & Iridium satellite \\
\hline
\end{tabular}

Table 2. Comparison between Seaglider and Deepglider Specifications.

\begin{tabular}{|c|c|c|}
\hline types & Seaglider & Deepglider \\
\hline Weight & $52 \mathrm{~kg}$ & $62 \mathrm{~kg}$ \\
\hline Hull Diameter & $30 \mathrm{~cm}$ & $30 \mathrm{~cm}$ \\
\hline Vehicle Length & $1.8 \mathrm{~m}$ & $1.8 \mathrm{~m}$ \\
\hline Wing Span & $1 \mathrm{~m}$ & $1 \mathrm{~m}$ \\
\hline Depth Range & $1000 \mathrm{~m}$ & $6000 \mathrm{~m}$ \\
\hline Payload & $25 \mathrm{~kg}$ & $25 \mathrm{~kg}$ \\
\hline Speed & $0.25 \mathrm{~m} / \mathrm{sec}(1 / 2 \mathrm{knot})$ horizontal & $0.25-0.35 \mathrm{~m} / \mathrm{sec}$ horizontal \\
\hline Energy & Lithium primary batteries & Lithium sulfuryl chloride batteries \\
\hline Range & $4600 \mathrm{~km}(3800 \mathrm{~km}$ proven mission $)$ & $8500 \mathrm{~km}$ \\
\hline Navigation & \multicolumn{2}{|c|}{ GPS, and internal dead reckoning, altimeter } \\
\hline Communications & \multicolumn{2}{|c|}{ Iridium satellite } \\
\hline
\end{tabular}


Table 3. Basic design patent.

\begin{tabular}{|l|l|l|}
\hline 11. Float & 21. Swimmer & 218. Rudder servo mechanism \\
\hline 111. Float Body & 211. Body & $\begin{array}{l}\text { 219. Rudder control } \\
\text { pass-through }\end{array}$ \\
\hline 112. Solar Panels & 212. Nose Cone & 220. Rudder control \\
\hline 113. GPS receiver & 213. Fin & 221. Rudder Arm \\
\hline 114. Antenna & 214. Fin System & 222. Rudder \\
\hline 115. Electronics box & 215. Electrical pass-through & 31. Tether \\
\hline 116. Rudder & 216. Batteries & 311. Tensile Member \\
\hline 217. Control Electronics & 312. Tensile Member \\
\hline
\end{tabular}

Table 4. specifications of wave glider.

\begin{tabular}{|c|c|}
\hline type & Wave glider \\
\hline Vehicle & Sub and Float joined by $7 \mathrm{~m}$ (20ft) tether \\
\hline Dimensions & Float: $208 \mathrm{~cm}$ x $60 \mathrm{~cm}$, Sub: $40 \mathrm{~cm}$ x $191 \mathrm{~cm}$, Wings: $107 \mathrm{~cm}$ wide \\
\hline Weight & Mass: $90 \mathrm{~kg}$, Displacement: $150 \mathrm{~kg}$ \\
\hline Water Speed & $1 \mathrm{~m} 0.4 \mathrm{kts}$ to $2.0 \mathrm{kts}$ (variable) \\
\hline Observability & $\begin{array}{c}\text { Silent propulsion system, Minimal visual \& radar signature Optionally increased by } \\
\text { visibility mast, marker light and radar target enhancer }\end{array}$ \\
\hline Energy & Individual batteries are isolated from each other, Automatic charge/discharge, cut-off \\
\hline Propulsion & Mechanical conversion of wave energy into forward propulsion \\
\hline Base payload & Water speed sensor, AIS receiver \\
\hline Solar power & 80 Watts (peak) for battery charging, onboard electronics \& payloads \\
\hline Communications & Iridium Satellite 9602 or 9522B, Short Burst Data and RUDICS, Cellular modem \\
\hline Navigation & GPS \\
\hline
\end{tabular}

Table 5. Wave glider performance vs sea state.

\begin{tabular}{|c|c|}
\hline \multicolumn{2}{|c|}{ Wave Glider propulsion speed performance } \\
\hline Flat Calm & $0 \mathrm{kts}$ \\
\hline Sea State 0 & 0.25 to $0.50 \mathrm{kts}$ \\
\hline Sea State 1 & 0.50 to $1.50 \mathrm{kts}$ \\
\hline Sea State 2 & 1.25 to $2.00 \mathrm{kts}$ \\
\hline Sea State $3+$ & 1.50 to $2.25 \mathrm{kts}$ \\
\hline Long Mission Average & $1.50 \mathrm{kts}$ \\
\hline
\end{tabular}

